\title{
Monitoring of environmental exposure to polycyclic aromatic hydrocarbons: a review
}

\author{
K. Srogi
}

Received: 20 January 2007/Accepted: 26 January 2007/Published online: 22 March 2007

(C) Springer-Verlag 2007

\begin{abstract}
Polycyclic aromatic hydrocarbons (PAHs) are a large group of organic compounds with two or more fused aromatic rings. They have a relatively low solubility in water, but are highly lipophilic. Most of the PAHs with low vapour pressure in the air are adsorbed on particles. When dissolved in water or adsorbed on particulate matter, PAHs can undergo photodecomposition when exposed to ultraviolet light from solar radiation. In the atmosphere, PAHs can react with pollutants such as ozone, nitrogen oxides and sulfur dioxide, yielding diones, nitro- and dinitroPAHs, and sulfonic acids, respectively. PAHs may also be degraded by some microorganisms in the soil. PAHs are widespread environmental contaminants resulting from incomplete combustion of organic materials. The occurrence is largely a result of anthropogenic emissions such as fossil fuel-burning, motor vehicle, waste incinerator, oil refining, coke and asphalt production, and aluminum production, etc. PAHs have received increased attention in recent years in air pollution studies because some of these compounds are highly carcinogenic or mutagenic. Eight PAHs (Car-PAHs) typically considered as possible carcinogens are: benzo(a)anthracene, chrysene, benzo(b) fluoranthene, benzo(k)fluoranthene, benzo(a)pyrene $(\mathrm{B}(\mathrm{a}) \mathrm{P})$, dibenzo(a,h)anthracene, indeno(1,2,3-cd)pyrene and benzo (g,h,i)perylene. In particular, benzo(a)pyrene has been identified as being highly carcinogenic. The US Environmental Protection Agency (EPA) has promulgated 16 unsubstituted PAHs (EPA-PAH) as priority pollutants. Thus, exposure assessments of PAHs in the developing world are important. The scope of this review will be to
\end{abstract}

K. Srogi $(\square)$

Institute for Chemical Processing of Coal,

Zamkowa 1, 41-803 Zabrze, Poland

e-mail: krystynasrogi@ poczta.onet.pl give an overview of PAH concentrations in various environmental samples and to discuss the advantages and limitations of applying these parameters in the assessment of environmental risks in ecosystems and human health. As it well known, there is an increasing trend to use the behavior of pollutants (i.e. bioaccumulation) as well as pollution-induced biological and biochemical effects on human organisms to evaluate or predict the impact of chemicals on ecosystems. Emphasis in this review will, therefore, be placed on the use of bioaccumulation and biomarker responses in air, soil, water and food, as monitoring tools for the assessment of the risks and hazards of PAH concentrations for the ecosystem, as well as on its limitations.

Keywords Polycyclic aromatic hydrocarbons - Plant . Soil - Sediment - Water · Food - Air · PAH biomonitoring · Seasonal trend $\cdot \mathrm{PM}_{2.5} \cdot \mathrm{PM}_{2.5-10} \cdot$ Pollution control

\section{Introduction}

Polycyclic aromatic hydrocarbons (PAHs) from incomplete combustion or pyrolysis organic material sources are ubiquitous in the global environment and are typically more concentrated near urban centers (Hyötyläinen and Oikari 2004). Therefore vehicular emissions may not be the only source of PAHs in these samples. Other possible sources are tire wear debris, asphalt particles (Binet et al. 2002) and stationary combustion sources or crematoria (Santasiero et al. 2005). Sources of PAHs in urban atmosphere include automobiles, re-suspended soils, refineries and power plants (Omar et al. 2002; Yang et al. 2002; Dyke et al. 2003). PAHs are also occurring in large amounts in sedimentary rocks and petroleum (Lichtfouse 
et al. 1997, 1999; Henner et al. 1999). Additional contributions to ambient air levels arise from tobacco smoking (Sakai et al. 2002), while the use of heating sources can increase PAH concentrations in indoor air (WHO 1987). Natural sources such as forest fires and volcanic eruptions are less important. Their fate is determined by their physico-chemical properties, especially nonpolarity and hydrophobicity responsible for their persistence in the environment. PAHs from fuel oils tend to be quickly adsorbed onto particles and to accumulate in sediments (Tolosa et al. 2004). PAH refers to a group of a few hundreds of compounds with two or more fused benzene rings.

PAHs have received increased attention in recent years in air pollution studies because some of these compounds are highly carcinogenic or mutagenic (IARC 1983). Eight PAHs (Car-PAHs) typically considered as possible carcinogens are: benzo(a)anthracene, chrysene, benzo(b)fluoranthene, benzo(k)fluoranthene, benzo(a)pyrene $(\mathrm{B}(\mathrm{a}) \mathrm{P})$, dibenzo(a,h)anthracene, indeno(1,2,3-cd)pyrene and benzo(g,h,i)perylene (Menzie et al. 1992). In particular, benzo(a)pyrene has been identified as being highly carcinogenic (Kuo et al. 1998; Wang et al. 2002). The US Environmental Protection Agency (EPA) has promulgated 16 unsubstituted PAHs (EPA-PAH) as priority pollutants.

To understand the extent of human exposure to $\mathrm{B}(\mathrm{a}) \mathrm{P}$ and other PAHs, reliable sampling and analytical methods are necessary (US EPA 1999). These indicate that particlebound PAHs are considered to be a significant hazardous substance to human health through breathing. In view of this health concern, monitoring the level of particle-bound PAHs in urban areas has become more important (Chetwittayachan et al. 2002). B(a)P is often used as a marker for total PAHs exposure in industry and in the environment (Lin et al. 2002). Because of its lowest boiling point and highest volatility, naphthalene occurs almost completely in the vapor-phase. Therefore, its surface deposition will be relatively small in comparison with other PAHs. The observed high levels of naphthalene in domestic environments in Taipei might be related to the popular use of camphor balls in the wardrobe ( $\mathrm{Li}$ and Ro 2000).

The highest concentrations of atmospheric PAHs can be found in the urban environment, due to the increasing vehicular traffic and the small dispersion of the atmospheric pollutants. The risk associated with human exposure to atmospheric PAHs is highest in the cities, considering the population density (Caricchia et al. 1999). Despite the drastic reduction of urban particulate pollution in cities resulting from the improvement of coal usage and the shift toward other fossil fuels (oil or natural gas) for domestic heating, the densification of the urban net combined with population growth and the increasing importance of traffic have contributed to reinforce urban particulate pollution. Furthermore, particles produced by cars are much smaller than coal particles and found in the breathable size fraction (Manoli et al. 2002). There is much information on the multi-ringed heavier PAHs but have left the lighter vapor-phase PAH components rather neglected. Although these lighter compounds have weaker carcinogenic/mutagenic properties, they are the most abundant in the urban atmosphere and react with other pollutants to form more toxic derivatives (Park et al. 2002). Thus, the implication of human exposure to mixtures of PAHs, rather than to individual substances, is important. The levels of individual PAHs vary over several orders of magnitude and are generally in the range between $<0.1$ and $100 \mathrm{ng} / \mathrm{m}^{3}$. PAHs are mainly adsorbed to airborne particulate matter (WHO 1998).

There are various industrial workplaces for which a significant increase of certain cancer diseases has been found that may be attributed to an unusually high exposure to PAH. For instance, PAH exposure is high in coke plants, coal tar and pitch producing and manufacturing industries, aluminium plants, iron and steel foundries, creosote-, rubber-, mineral oil-, soot- and carbon black-producing or manufacturing companies. As highly exposed occupational groups, chimney sweeps, roadmen (pavement-tarring) and roofers (roof-tarring) are also under increased risk (Jacob and Seidel 2002). Automotive byproducts are a common denominator for many observations for both PAHs and metals. The motor vehicle is increasingly recognized as a contributor to air pollution. Motorized vehicle emissions are strongly associated with health problems as shown by research on how proximity to roads affects mortality (Hoek et al. 2002). Brunekreef and Holgate (2002) reviewed the health consequences of air pollution and demonstrate a strong association between air pollution, asthma and chronic obstructive pulmonary disease. The PAHs exhausted as fine particles by motor vehicles are deposited in and accumulate in soil. Comparing busy streets with residential streets in the inner-city and in the suburbs provides evidence about the importance of motor traffic as a source of soil PAHs.

Generally, environmental exposure of organisms is assessed by monitoring their environment (sediment/soil, water, and air). Biomonitoring, however, can provide an assessment of the integrated uptake through all exposure routes. This is important since only the bioavailable chemical is likely to be assimilated/concentrated in tissues, body fluids, and excreta. Owing to the complexity of biological samples, however, intricate analytical protocols are traditionally used for analyses. Conventional biomonitoring methods are often time-consuming, labor intensive, and expensive. Currently, urinary 1-OHP is tested as biomarker for the assessment of low level PAHs exposure of general population. Reports by Vyskocil et al. (1997), Zhao et al. (1992) Kanoh et al. (1993) and Jongeneelen (1994) 
suggested that levels of 1-OHP reflect the levels of environmental PAH exposure from different sources such as air, food and the environment of the home life. However, in study (Vyskocil et al. 1997), it was shown that other factors than air pollution contribute more substantially to overall exposure to PAH and it was speculated that diet could be one of the most important factors. For example, the highest peak of 1-OH pyrene and benzo(a)pyrene-type metabolite concentrations, were found in significantly elevated levels in the bile of cat-shark collected in Lenga in San Vicente Bay. These probably reflect boat traffic and combustion-based (steel, petrochemical) industries present in these areas. However, the naphthalene-type metabolites were found in all sampled cat-shark bile in the assessed areas, reflecting that petrogenic $\mathrm{PAH}$ are ubiquitous in the whole embayment system of Chile (Fuentes-Rios et al. 2005). Cormier et al. (2000) reported a similar situation in white sucker from Ohio state (USA), where naphthalenetype metabolites were detected in all sampled fish bile including fish from the reference areas.

The scope of this review will be to give an overview of PAH concentrations in various environmental samples and to discuss the advantages and limitations of applying these parameters in the assessment of environmental risks in ecosystems and human health. As it well known, there is an increasing trend to use the behavior of pollutants (i.e. bioaccumulation) as well as pollution-induced biological and biochemical effects on human organisms to evaluate or predict the impact of chemicals on ecosystems. Emphasis in this review will, therefore, be placed on the use of bioaccumulation and biomarker responses in air, soil, water and food, as monitoring tools for the assessment of the risks and hazards of PAH concentrations for the ecosystem, as well as on its limitations.

\section{Exposure to PAH}

The composition of PAHs in association with airborne particles changes significantly according to their emission sources, e.g. traffic or other processes of combustion. PAH concentration ratios can be used to identify possible emission sources (Li and Kamens 1993; Venkataraman et al. 1994). Exposure to indoor particulate matter (PM) has been recognized as a significant health problem since most people spend approximately $90 \%$ of their time indoors. Particles of concern to human health are those known as inhalable particles $\left(\mathrm{PM}_{2.5}, \mathrm{PM}\right.$ with aerodynamic diameter less than $2.5 \mu \mathrm{m})$. Most particulate-phase PAH are adsorbed onto fine particles $(<2.5 \mu \mathrm{m})$, which are deposited slowly and, depending on atmospheric conditions and chemical reactivity, may be transported over long distances and pollute even remote areas. PAHs on particles less than $1 \mu \mathrm{m}$ were result from combustion and other high temperature sources (Sheu et al. 1997; Kiss et al. 1998).

As it well-know low molecular weight PAHs (two- and three-rings) occur in the atmosphere in the vapour phase whereas multi-ringed PAHs (five-rings) are bound to particles. Intermediate molecular weight $\mathrm{PAHs}$ (four-rings) are partitioned between the vapour and particulate phases, depending on atmospheric temperature (Howsam et al. 2000, 2001).

In the following sections, main sources of PAHs in ecosystem include plants, air, water, food and soils will be described.

Plants

Many plants have a relatively large surface area covered with waxes that facilitates the accumulation of hydrophobic chemicals. The use of plants as passive samplers of organic compounds in the atmospheric has been suggested by many authors (Niu et al. 2003; De Nicola et al. 2005; Lodovici et al. 1998; Müller et al. 2001). Indeed, PAHs are characterised by a low to moderate volatility according to their molecular weight (Sverdrup et al. 2003). Moreover, Schreiber and Schönherr (1992) reported that the main factor affecting the absorption of volatilized PAHs through the cuticle is the extent of leaf area exposed to the atmosphere.

PAHs from a polluted atmosphere are generally transferred to plants by particle-phase deposition on the waxy leaf cuticle or by uptake in the gas phase through stomata (Kipopoulou et al. 1999; Lehndorff and Schwark 2004). Leaf features (surface, cuticular waxes, hairs, number of stomata) play an important role in PAH uptake and accumulation (Jouraeva et al. 2002). Howsam et al. (2000) found higher PAH concentrations in hairy leaves compared to hairless leaves collected in the same area. Hairs increase the leaf surface that is able to capture particulate from the air; in addition hairs favour a boundary layer of stagnant air on the leaf surface, improving particle retention (Rauret et al. 1994). Moreover, some studies highlight the role of other leaf components, such as lipids and epicuticular waxes, in leaf accumulation of PAHs that are lipophilic compounds (Howsam et al. 2000). Besides emission sources, PAH air concentrations depend also on atmospheric conditions (Menichini 1992; Caricchia et al. 1999). Indeed, the highest PAH air concentrations are measured in winter due to the larger number of emission sources (De Nicola et al. 2005), the stability of atmospheric conditions and the presence of fewer degradation phenomena (Menichini 1992; Park et al. 2002). For example, total PAH concentrations in Quercus ilex leaves collected in Naples showed a clear temporal trend, with the highest values in winter, comparable to the trend found in PAH airborne particulate. 
At the control site leaf PAH concentrations [from 300 (September 2001 and May 2002) to $500 \mathrm{ng} / \mathrm{g} \mathrm{dw}$-May 2001 and January 2002] showed lower values and smaller temporal variations than the urban sites (the concentrations of leaf total PAHs ranged from 1,100 to $2,076 \mathrm{ng} / \mathrm{g} \mathrm{dw}$ in May 2001, from 1,349 to $1,930 \mathrm{ng} / \mathrm{g} \mathrm{dw}$ in September 2001 and from 1,038 to $1,962 \mathrm{ng} / \mathrm{g} \mathrm{dw}$ in May 2002). This suggests the ability of Quercus ilex leaves to act as monitors of PAH gradients in time despite the variation in leaf morphological features due to plant phenology. The high leaf concentrations of total PAHs in January are mainly attributable to the contribution of medium molecular weight PAHs to the total (De Nicola et al. 2005).

The temporal trend agreed with the seasonal variations observed in PAH leaf concentrations by other authors (Nakajima et al. 1995; Lodovici et al. 1998). Seasonal variations in concentrations of PAHs with higher values in winter than in summer are found in Azalea leaves (Nakajima et al. 1995) and in leaves of Laurus nobilis collected in different sites of Tuscany (Lodovici et al. 1998). PAH leaf concentrations were on average twofold higher in leaves collected in the winter samplings. Although it was not possible to establish a linear quantitative relationships between leaf and air PAH concentrations, the higher values detected in winter might be attributable to a greater deposition of these contaminants on leaf surface, due to a large number of emission sources (Menichini 1992), increased atmospheric stability (Caricchia et al. 1999), greater condensation (Simonich and Hites 1995) and lesser photolysis processes (Papageorgopoulou et al. 1999). Niu et al. (2003) highlighted for spruce needles, that show leaf surface rich in wax components, an enhanced photolysis of PAHs under sunlight irradiation.

PAHs can also enter plant tissues by partitioning from contaminated soil to the roots and translocation into the shoot. However, the extent of PAH uptake by roots is still debated in the literature: because of their high lipophility and low solubility, PAHs would be adsorbed through the epidermis of roots in contact with soil particles, but not drawn along the inner root (Kipopoulou et al. 1999). By contrast, Fismes et al. (2002) reported a direct relationship between PAH concentrations in soil and plants or tree Laurus nobolis (Lodovici et al. 1998) and suggested a soilto-root transfer predominant upon the atmosphere-to-plant pathway. Heavy pollutions of halophytic plants, especially Salicornia species, have been reported further to the significant impacts of sediments by fuel oil (Meudec et al. 2006). The edible Salicornia fragilis being common along the Atlantic coast of Europe is potentially exposed to accidental marine pollution because of its low localisation on intertidal area.

Meudec et al., (2006) reported the bioaccumulation of PAHs from oil-polluted sediments in the shoots of Sali- cornia fragilis. As high concentrations of PAH were detected in plants, and a soil-root-shoot transfer was suggested. Total PAHs concentrations in Salicornia fragilis tissues were from 3.5 to $40.9 \mathrm{mg} / \mathrm{kg} \mathrm{dw}$. As expected, the highest concentration was recorded in plants grown on the most polluted sediment. Total PAHs in roots of plants exposed to $0.2 \%$ were found to be $33.5 \mathrm{mg} / \mathrm{kg} \mathrm{dw}$, about ten times the level in shoots (Meudec et al. 2006). PAH compounds at concentrations of up to $43 \mu \mathrm{g} / \mathrm{g}$ (naphthalene) were detected in roots and up to $0.2 \mu \mathrm{g} / \mathrm{g}$ (naphthalene) in leaves of plants (Spartina alterniflora) grown in pots of contaminated soil. The concentrations in the roots are one to two orders of magnitude lower than the concentrations in the soil and are linearly related to the soil concentrations. The concentrations in the leaves are very low-three to four orders of magnitude lower than the soil, and do not have a direct linear relationship to the soil concentrations No difference was found in leaf PAH concentrations between plants grown in contaminated water and control plants (Watts et al. 2006).

According to Kipopoulou et al. (1999), the strong adsorption of high-weight PAHs upon the root epidermis would prevent them from being drawn into the inner root conversely to low- and medium-weight PAHs. This theory is contradicted by the study of Fismes et al. (2002) who found high abundance in foliar extracts of high-weight benzo(a)pyrene or benzo(ghi)perylene, after translocation from roots to aerial parts (Meudec et al. 2006).

Henner et al. (1999) identified plants growing on soils from three ancient gasworks, from an ancient coking factory and from a prepared decontamination bed filled with gas-work soil. All plants were typical pioneer weeds that were commonly found in heterogeneous, low fertility soils. They were well adapted to drought and all showed a dense, deep root network, even through "aged" tars. Observation of tar shows of weathered soils in industrial fields revealed that the location of the contamination can be very heterogeneous, some areas being highly polluted while others much less. Nonetheless, all locations showed a wellflourishing vegetation, some what enhanced by fertilisers at the decontamination bed. Noteworthy, at some locations, plants were even able to grow roots through "aged", nonsmelling solid tar layers located at about $3 \pm 10 \mathrm{~cm}$ depth. There were only two exceptions showing the absence of plants: first, a small soil area, e.g. $20 \mathrm{~m}^{2}$, located at an ancient gaswork field, where high amounts of foul smelling liquid tar occur between 0 and $20 \mathrm{~cm}$ depth, and second, a hillock of several tons of "benzene smelling" gas-work soils which had been excavated 6 months ago. They concluded that the inhibition of plant growth is due to volatile, water-soluble compounds.

Grasses and annual herbs have been the primary focus of experiments evaluating the potential of plants to remediate 
PAH contaminated soils (Davis et al. 2002). Trees have received very little attention with regard to PAHs, although their perennial life-history and extensive root systems suggest they may be desirable for use in phytoremediation. It has also been speculated that trees may have greater rates of rhizodeposition (Grayston et al. 1996) including fine root turnover (Gill and Jackson 2000) and exudation. For example, the total PAH concentrations in Melaleuca leaves from the urban background and in grass were lower than PAH levels determined in sugar maple leaves and white pine needles collected from suburban and urban areas of the USA (Simonich and Hites 1995), while the leaves in the Melaleuca leaves collected close to the major intersection were higher (Müller et al. 2001).

According to Domeňo et al. (2006) lichens could be used as good bioindicators of air pollution. Twelve out of the 16 PAHs studied were found in lichens Xanthoria parietina samples. All of them in a concentration range from 25 to $40 \mathrm{ng} / \mathrm{g}$. The highest concentrations in lichens Xanthoria parietina were found for dibenzo(a,h)anthracene and benzo(k)fluoranthene, followed by benzo(a)anthracene, chrysene and fluorene. The reason of non-detection in lichens of other PAHs (five or more rings in their structure) present in the atmosphere in high concentrations may be of being almost exclusively adsorbed on suspended particulate matter. Concerning the origin of the PAHs found in the lichen, benzo(a)pyrene is usually emitted from catalyst and noncatalyst automobiles. Benzo(a)anthracene and chrysene are often resulted from the combustion of both diesel and natural gas. In both cases the origin suggests the traffic road as a major source of these compounds, which fits to other studies in which benzo(a)pyrene and dibenzo(a,h)anthracene indicate traffic emission and identify traffic as the main source of urban PAH emission. Also, Capuano et al. (2005) the highest PAH value $(101.3 \mathrm{ng} / \mathrm{g})$ in the pine needles was observed, coming from a pine tree situated close to a heavily congested road. The concentration of PAHs was highest in the needles collected during the soot episodes when $140 \mathrm{ng} / \mathrm{g} \mathrm{dw}$ was found, which was significantly higher than the $32 \mathrm{ng} / \mathrm{g} \mathrm{dw}$ measured during the same period in 1992. In addition, a greater proportion of non-volatile PAHs, which in the atmosphere are mainly associated on particles, were found in the needles collected in connection with the soot episodes. Consequently, PAHs in the particle phase appeared to be an important parameter governing the uptake of PAH in the needles.

The concentrations of PAHs found in the different compartments of environmnet (Brorström-Lundén and Löfgren 1998) are shown in Table 1. The authors were found that the content of PAHs in the spruce needles was highest in the samples collected in January-February, when compared with the needles collected in April-May.
Table 1 The concentrations of PAHs found in the different compartments of environment (Brorström-Lundén and Löfgren 1998)

\begin{tabular}{llcc}
\hline $\begin{array}{l}\text { Period (1995) } \\
\text { Ambient (C) }\end{array}$ & Site 1 & Site 2 \\
Precipitation (mm) & & & \\
\hline Air & $\mathrm{ng} \mathrm{m}^{-3}$ & 4.7 & 2.2 \\
Spruce nedles & & & \\
Forest edge & $\mathrm{ng} \mathrm{g}^{-1} \mathrm{dw}^{-1}$ & 41 & 28 \\
Inside the forest & $\mathrm{ng} \mathrm{g}^{-1} \mathrm{dw}^{-1}$ & 38 & 24 \\
Deposition & & & \\
Open fidel & $\mathrm{ng} \mathrm{m}^{-2} \mathrm{day}^{-1}$ & 370 & 360 \\
Thoughfall & $\mathrm{ng} \mathrm{m}^{-2} \mathrm{day}^{-1}$ & 500 & 700 \\
Litterfall & $\mathrm{ng} \mathrm{g}^{-1} \mathrm{dw}^{-1}$ & 200 & 200 \\
Run-off & $\mathrm{ng} \mathrm{L}^{-1}$ & 4.3 & 3.9 \\
Sil (humus) & $\mathrm{ng} \mathrm{g}^{-1} \mathrm{dw}^{-1}$ & $\mathrm{ND}$ & 2,500 \\
\hline
\end{tabular}

The total concentrations in plant samples from other urban and industrial areas are shown in Table 2 (Bakker et al. 2000). The variation in plant concentrations is large, arising from differences between species, differences between sampled plant organs (needles, leaves and fruit) and differences in sample treatment. For example, washing of the plant surfaces has a large influence on concentrations of particle-bound PAHs.

\section{Food}

Food appears to be the main source of PAH intake for humans not occupationally exposed to PAH. Consumers might be exposed to PAHs by eating grilled or charred meats, contaminated cereals, flour, bread and vegetables (Grova et al. 2006). In vivo studies suggest a transfer in intestinal epithelium by diffusion, which appears extensively governed by the physicochemical properties of PAHs, particularly lipophilicity. However, other mechanisms, such as metabolism, are considered to intervene (Cavret and Feidt 2005; Phillips 1999).

It should be noted that, food-animal transfer pathways of PAHs are so far poorly known due to the absence, of investigations involving tracers (Laurent et al. 2001). For example, Laurent et al. (2002) reported a study of portal absorption of PAHs using two ${ }^{14} \mathrm{C}$-tagged compounds: ${ }^{14} \mathrm{C}$ phenanthrene and ${ }^{14} \mathrm{C}$-benzo(a)pyrene in the growing pig. These two compounds differ either by the lipophilicity, either by the water solubility, either by fused benzene rings number. The analysis of portal and arterial blood radioactivity showed that both PAHs were absorbed with a maximum concentration at 4-6 h, or 5-6 h after milk ingestion. Then, the blood radioactivity decreased to reach background levels $24 \mathrm{~h}$ after milk ingestion. Furthermore, the portal and arterial blood radioactivities were higher for 
Table 2 Total concentrations of PAHs plants (ng/g dry wt.) in (sub)urban areas and in the vicinity of human (industrial) activities (after Bakker et al. 2000)

\section{a Washed leaves}

b Original concentrations expressed in $\mu \mathrm{g} g$ fresh wt. converted to $\mu \mathrm{g} / \mathrm{g}$ dry wt. assuming a fresh wt. dry wt. of 10

${ }^{c}$ Concentration correlated to number of inhabitants

${ }^{\mathrm{d}}$ Highest concentration

\begin{tabular}{|c|c|c|c|c|}
\hline Location & $\begin{array}{l}\text { Number } \\
\text { of PAH's }\end{array}$ & Plant & $\begin{array}{l}\sum \mathrm{PAH} \\
\text { concentration } \\
\text { in plant } \\
\text { (ng g dry wt.) }\end{array}$ & Reference \\
\hline Highway (S) & 16 & Lettuce & $17-90$ & Larssen and Sahlberg (1982) \\
\hline Highway (CAN) & 17 & $\begin{array}{l}\text { Onions }^{\mathrm{a}}, \text { beet }^{\mathrm{a}}, \\
\text { tomatoes }^{\mathrm{a}}\end{array}$ & $10-1,900^{\mathrm{b}}$ & Wang and Meresz (1982) \\
\hline Al smelter $(\mathrm{S})$ & 16 & Lettuce & $320-920$ & Larsen and Sahlberg (1982) \\
\hline Highway (S) & 16 & Kale & $\begin{array}{l}500(\text { at } 50 \mathrm{~m})^{\mathrm{b}} \\
5,000(\text { at } 10 \mathrm{~m})^{\mathrm{b}}\end{array}$ & $\begin{array}{l}\text { Brorström-Lunden and } \\
\text { Skärby (1984) }\end{array}$ \\
\hline Busy city street (S) & 16 & Kale & $\begin{array}{l}5,000(\text { at } 50 \mathrm{~m})^{\mathrm{b}} \\
14,000(\text { at } 10 \mathrm{~m})^{\mathrm{b}}\end{array}$ & $\begin{array}{l}\text { Brorström-Lunden and } \\
\text { Skärby (1984) }\end{array}$ \\
\hline Urban (USA) & 10 & Pine & $800-1,600$ & Simonich and Hites (1994) \\
\hline Urban (USA) & 10 & sugar maple & $500-1,100$ & Simonich and Hites (1994) \\
\hline Urban (I) & 10 & Bay tree ${ }^{a}$ & $73-880$ & Lodovici et al. (1994) \\
\hline Suburban (UK) & 16 & Pine & $20-3,100^{\mathrm{c}}$ & Tremolada et al. (1996) \\
\hline Suburban (USA) & 18 & Maple & $510 \pm 100$ & $\begin{array}{l}\text { Wagrowski and Hites } \\
\text { (1997) }\end{array}$ \\
\hline Urban (USA) & 18 & Maple & $1600 \pm 210$ & $\begin{array}{l}\text { Wagrowski and Hites } \\
\text { (1997) }\end{array}$ \\
\hline Urban (RBD) & 13 & Kale & $1,000-5,000$ & Franzaring (1997) \\
\hline Urban (UK) & 16 & Grass & $153 \pm 8$ & Meharg et a.l (1998) \\
\hline Polyprop.fire (UK) & 16 & Grass & $2,400^{\mathrm{d}}$ & Meharg et al. (1998) \\
\hline Industrial (GR) & 16 & $\begin{array}{l}\text { Various } \\
\text { vegetables }^{\mathrm{a}}\end{array}$ & $25-239$ & Kipopoulou et al. (1999) \\
\hline
\end{tabular}

phenanthrene (even if the injected load was the lowest) than these of benzo(a)pyrene, in agreement with their lipophilicity and water solubility difference (Laurent et al. 2001). Main ${ }^{14} \mathrm{C}$ absorption occurred during the $1-3 \mathrm{~h}$ time period after ingestion for ${ }^{14} \mathrm{C}$-phenanthrene and during the 3-6 h time period for ${ }^{14} \mathrm{C}$-benzo(a)pyrene. ${ }^{14} \mathrm{C}$ portal absorption rate was high for ${ }^{14} \mathrm{C}$-phenanthrene $(95 \%)$, it was close to $33 \%$ for ${ }^{14} \mathrm{C}$-benzo(a)pyrene (9\%). These results indicate that the two studied molecules have a quite different behaviour during digestion and absorption. Phenanthrene is greatly absorbed and its absorption occurs via the blood system, whereas benzo(a)pyrene was partly and weakly absorbed respectively. However, these two molecules are mainly absorbed via the portal vein.

Concentrations of benzo(a)pyrene in meat and meat products have been restricted to $1 \mu \mathrm{g} / \mathrm{kg}$ in Germany and for food and beverages to $30 \mathrm{ng} / \mathrm{kg}$ in Italy. Most of the foodstuffs are less contaminated so that $1 \mu \mathrm{g} / \mathrm{kg}$ rather appears to be a pessimistic value, although occasionally far higher concentrations have been found, especially in marine food (oysters, mussels, smoked fish) and vegetables (green kale). The maximum daily benzo(a)pyrene intake from food can be extrapolated to be $1 \mu \mathrm{g}$ (Jacob and Seidel 2002).

Kishikawa et al. (2003) reported that the average concentrations of total PAHs in commercial milk, infant formula and human milk were $0.99,2.01$ and $0.75 \mu \mathrm{g} / \mathrm{kg}$, respectively. Several studies achieved in environmental conditions show that PAHs can be excreted in the milk of ruminants (Grova et al. 2000, 2006). Grova et al. (2006) reported the impact of chronic exposure to PAHs on milk contamination was evaluated by oral administration of a mixture of fluorene, phenanthrene, anthracene, fluoranthene, pyrene, chrysene, benzo(k)fluorene, benzo(a)pyrene and benzo(g,h,i)perylene at $0.02 \mathrm{mg} / \mathrm{kg}$ to lactating goats for 28 days. The results evidence several major points: (1) benzo(k)fluorene, benzo(a)pyrene and benzo(g,h,i)perylene were not detected in the milk; (2) unexpectedly, the concentration of fluorene, phenanthrene, anthracene, fluoranthene, pyrene and chrysene did not change with time; (3) monohydroxylated PAH metabolites (-OH), namely 2-OH-fluorene, 3-OH-phenanthrene and 1-OH-pyrene were detected shortly after administration. The concentrations of 2-OH-fluorene and 3-OH-phenanthrene reached, respectively, maxima of 0.41 and $0.22 \mathrm{ng} / \mathrm{mL}$ during the first exposure week, whereas the concentration of 1-OH pyrene increased to reach a maximum of $0.97 \mathrm{ng} / \mathrm{mL}$ on day 14 , then slightly decreased during the last two exposure weeks. Those findings suggest a lack of activation of a metabolism that could lead to an excretion of PAHs into milk under native forms. However, a slight increase in concentration could induce the metabolism, which should lead to an 
increase in the excretion of metabolites into the milk. In spite of the absence of a significant transfer of parent PAHs to milk, the appearance of metabolites in milk raises questions of their impact on human health.

Also, cereal products may contain high levels of PAH because of drying methods. Cereals and vegetables are the major dietary sources of PAHs-except for high consumption of meat cooked over an open flame (Phillips 1999). Fiedler et al. (2002) examined green tea leaves, and they found that the total PAH concentrations of samples ranged from 497 to $517 \mu \mathrm{g} / \mathrm{kg}$, compared with brick tea leaves ranged from 1,048 to $1,162 \mu \mathrm{g} / \mathrm{kg}$. These concentrations are comparable to those in vegetation grown along the motorway $(772 \mu \mathrm{g} / \mathrm{kg})$ and an urban area $(1,901 \mu \mathrm{g} / \mathrm{kg})$ at North West Italy (Ardito et al. 1999).

The bioavailability of organic trace pollutants adsorbed to sediments is rather low, polluted sediments still represent an important source of contamination for freshwater animals. Bioaccumulation of compounds in fish (Reynolds et al. 2003), therefore, is a result of the different uptake and elimination processes of the compounds combined with metabolic clearance (biotransformation) (Verweij et al. 2004). Recently, Kong et al. (2005) examined tilapia (Oreochromis mossambicus), a freshwater fish purchased from the markets in Hong Kong (with fish supplied from the mainland) showed higher concentrations of PAHs $(76.5 \mathrm{ng} / \mathrm{g}$ wet wt) than those collected from Hong Kong fish ponds (60.1 ng/g wet wt). This suggested that the fishponds in the mainland may be more polluted due to the rapid socio-economic development in the region during the past 20 years. In another works catfish (Clarias fuscus) exhibited the highest concentrations of total PAHs in ventral muscle among ten fish species. Grass carp, mud crap and bighead carp had low concentrations of PAHs. Among marine fish species, no significant difference was observed among different species and between ventral and axial muscles in tissue concentrations of total PAHs. The concentrations of total PAHs in the muscles ranged from 15.5 to $118 \mathrm{ng} / \mathrm{g}$ wet wt. It also shows that the percentage of each $\mathrm{PAH}$ congener in different species of freshwater and marine fish. Nearly all the 16 PAHs except benzo(a)pyrene, indeno(1,2,3-cd)pyrene, dibenzo(a,h)anthracene and benzo $(\mathrm{g}, \mathrm{h}, \mathrm{i})$ perylene were detected in the fish samples. Higher percentages of two- and three-rings PAHs were found in all species. For example, naphthalene had the highest proportion among all compounds in both ventral and axial muscles of freshwater and marine fish, ranging from 14 to $72 \%$ of total PAHs. However, no significant difference in the distribution of PAHs between ventral and axial muscles was observed in marine fish. Among different congeners of PAHs, two-ring (naphtalene) and three-ring $\mathrm{PAH}$ (phenanthrene and fluorene) dominated the distribution in fish muscles (Cheung et al. 2007). Naphthalene was the most prevalent parent compound (22-72\% in marine fish and $14-52 \%$ in freshwater fish) because it has a higher solubility than other congeners with a larger molecular weight of PAHs.

Polycyclic aromatic hydrocarbons were also analyzed in fish: Mullus barbatus, Scomber scombrus, Micromesistius poutassou and Merluccius merluccius) in several pools coming from the Central Adriatic Sea. Atlantic mackerel, European hake and blue whiting showed the highest $\mathrm{PAH}$ concentrations, ranging from 44.1 to $63.3 \mathrm{ng} / \mathrm{g} \mathrm{wt}$, the group of invertebrate organisms showed a level of contamination about three times lower than those of the vertebrate groups (Perugini et al. 2007).

It should be noted that the bioaccumulation of PAHs by various marine organisms has been extensively reviewed by Meador et al. (1995). BSAFs of different PAH compounds in fish are listed in Table 3 (Van der Oost et al. 2003). BSAFs for the PAHs were calculated as the lipidnormalised $\mathrm{PAH}$ concentration in the bivalves divided by the TOC-normalised PAH concentration in the sediments BSAFkg OC/kg lipid $=\left(C_{\mathrm{o}} / f_{1}\right) /\left(C_{\mathrm{s}} / f_{\mathrm{OC}}\right)$-where $C_{\mathrm{o}}$ is the concentration of contaminant in the organism (both wet and dry weight commonly used), $C_{\mathrm{s}}$ is the contaminant concentration in the sediment (generally dry weight), $f_{1}$ is the lipid fraction of the tissue, and $f_{\mathrm{OC}}$ is the organic carbon fraction of the sediment (Simpson et al. 2006).

Vyskocil et al. (2000) demonstrated that food consumption represents the main source of PAH exposure for the children even in the big cities that are not heavily polluted by PAH from industrial sources. Some published reports become available of other studies of multipathway PAH exposure. Butler et al. (1993) measured personal exposure to benzo(a)pyrene in 15 adult individuals living in a town (population of 17,000) in New Jersey (USA). Compared to dietary exposures, the proportional contribution of inhalation exposures during late summer was about 5\%, which corresponds well to results of study performed by Vyskocil et al. (2000). Also Van Rooij et al. (1994) demonstrated in the study on Netherlands adult volunteers that the inhalation of ambient air is relatively unimportant for total pyrene intake accounting for less than 1\%. Lodovici et al. (1995) compared total dietary and inhalation PAH intake for adult population living in a town of medium size in central Italy (the average of the sum of $15 \mathrm{PAH}$ was $27 \mathrm{ng} / \mathrm{m}^{3}$ ). The intake by inhalation was $11 \%$ of the total intake. All these results confirm that food is the major source of exposure of humans to PAH in areas which are not highly polluted by PAH.

In summary, Phillips (1999) in your paper considered the current state of knowledge regarding the relative importance of different sources of PAHs to diet and the use of biomarkers to detect human exposure to PAHs. 


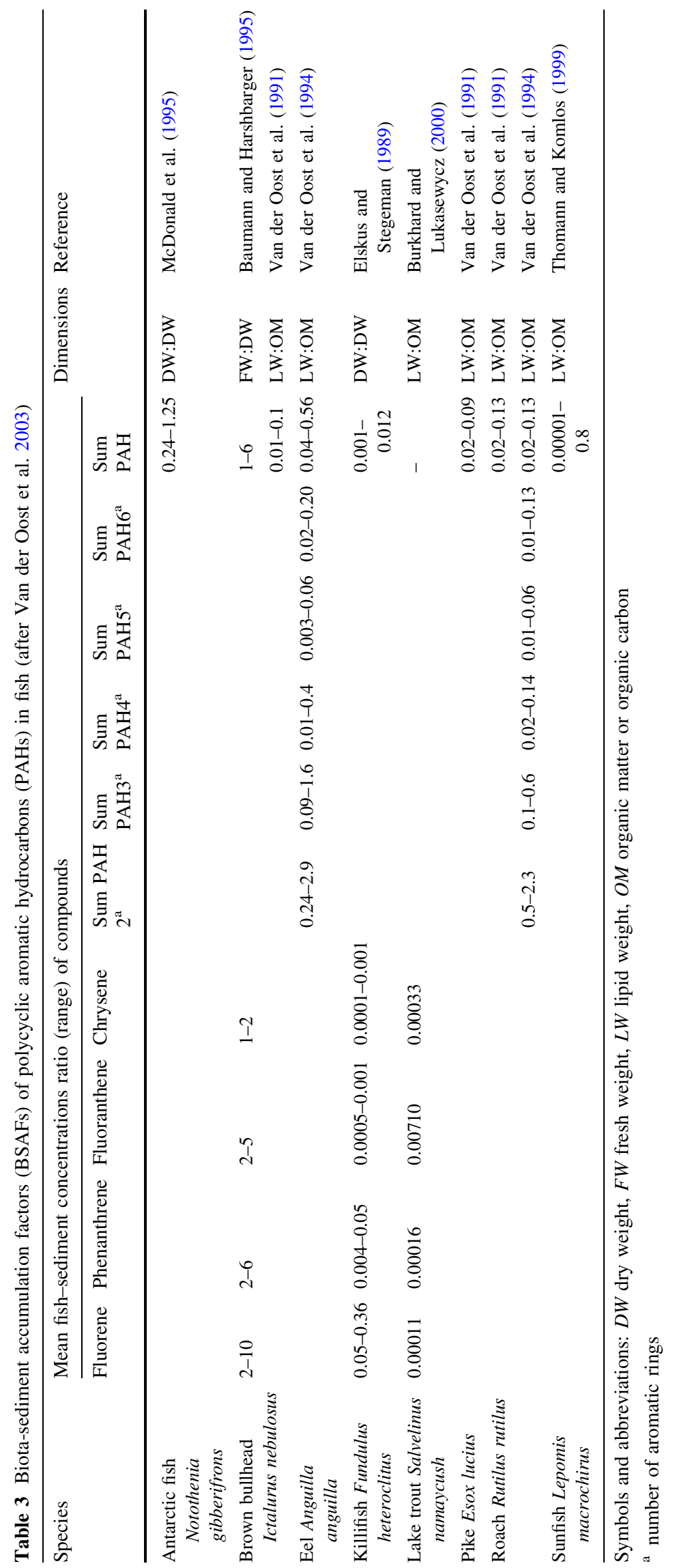




\section{Water}

PAHs enter surface waters mainly via atmospheric fallout, urban run-off, municipal effluents, industrial effluents and oil spillage or leakage. Atmospheric fallout includes wet and dry deposition of particles and vapors. PAHs, as semivolatile organic compounds, exist in both the gaseous and the particulate phase in air, and are subject to both vapor and particle washout from the atmosphere during precipitation. Atmospheric deposition is considered to be an important input of PAHs to surface waters. It has been estimated that $10-80 \%$ of PAH inputs to the world's oceans is from atmospheric sources. As a consequence, urban run-off contains PAHs deposited on surfaces, as well as mobile-related PAHs from gasoline and oil drips or spills, exhaust products, tyre particles, and bitumen from road surfaces. Higher concentrations of PAHs in urban runoff were found during autumn and winter, due to the high incidence of vehicles in the streets, coupled with the use of heating systems (Manoli and Samara 1999).

In another study concerning the distribution and the budget of PAHs in western Mediterranean seawater, it has been found that PAH content in the dissolved phase was maximal off-shore of Barcelona $(1,800 \mathrm{pg} / \mathrm{L})$ and in the Ebro river plume $(2,170 \mathrm{pg} / \mathrm{L})$, while concentrations in remote stations were lower (400-890 pg/L). PAHs associated with suspended particulate matter were evenly distributed in subsurface waters, and their concentrations ranged from 200 to $750 \mathrm{pg} / \mathrm{L}$, maximizing at the Gibraltar and Sicilian Straits and at a frontal zone located midway between the Iberian Peninsula and the Balearic Islands. Slightly higher concentrations were found at the continental shelf (457-772 pg/L) than in the open sea $(212-$ $605 \mathrm{pg} / \mathrm{L}$ ) (Dachs et al. 1997). Higher concentrations for dissolved-phase PAHs have also been observed in the Rhone delta, NW Mediterranean. PAHs in the dissolved phase were found up to 30 and $50 \mathrm{ng} / \mathrm{L}$ in summer and winter, respectively, whereas the corresponding particulate concentrations were much lower (up to 14 and $19 \mathrm{ng} / \mathrm{L}$ ) (Bouloubassi and Saliot 1991).

According to the World Health Organization study in 1997, the concentration of individual PAHs in surface and coastal waters is generally in the neighborhood of $0.05 \mu \mathrm{g} /$ $\mathrm{L}$ and concentration above this point indicates some contamination; also, a study carried out by the World Health Organization in 1993 revealed that benzo(a)pyrene concentration of $0.7 \mu \mathrm{g} / \mathrm{L}$ corresponds to an excess lifetime cancer risk of 10-5. According to studies done in the USA, in four major cities, the total PAHs in drinking water ranged between 4.7 and $600 \mu \mathrm{g} / \mathrm{L}$ (ASTDR 1995) as against obtained by Anyakora et al. (2005) (see Table 4). As shown in Table 4. the high-molecular-mass PAHs such as benzo(ghi)perylene, dibenzo(a,h)anthracene and
Table 4 PAHs concentration in water (Anyakora et al. 2005)

\begin{tabular}{ll}
\hline Compound & Water $(\mu \mathrm{g} / \mathrm{ml})$ \\
\hline Naphthalene & 0.55 \\
Acenapthylene & 0.34 \\
Acenapthene & 0.4 \\
Flourene & 0.33 \\
Phenanthrene & 1.46 \\
Anthracene & 0.35 \\
Flouranthene & 0.54 \\
Pyrene & 0.67 \\
Benz[a]anthracene & 0.56 \\
Chrysene & 1.32 \\
Benzo[b]flouranthene & 2.38 \\
Benzo[k]flouranthene & 1.82 \\
Benzo[a]pyrene & 1.72 \\
Dibenz[a,h]anthracene & 0 \\
Benzo[ghi]perylene & 0 \\
Indeno[1,2,3-cd]pyrene & 0 \\
\hline
\end{tabular}

indeno(1,2,3-cd)pyrene were not detected in the water sample. This can be attributed to their lower water solubility.

Groundwater is naturally filtered as it flows through various soil matrices, and PAHs adsorb well to organic soil. Groundwater concentrations of carcinogenic PAHs reported for US groundwaters ranged from 0.2 to $6.9 \mathrm{ng} / \mathrm{L}$, while the corresponding concentrations in surface waters were between 0.1 and $800 \mathrm{ng} / \mathrm{L}$ and most frequently between 2 and $50 \mathrm{ng} / \mathrm{L}$ (Menzie et al. 1992). Regarding the chlorination of drinking water, it has been found that this disinfection technique may lead to formation of oxygenated and chlorinated PAHs, i.e. compounds that are more toxic than the parent PAHs (Manoli and Samara 1999).

The presence of PAHs in drinking water may be due to the surface or groundwater used as raw water sources, or to the use of coal tar-coated pipes in public water supply systems, European Community directive 80/778/EEC (1980) states a maximum level for PAHs in drinking water of $0.2 \mu \mathrm{g} / \mathrm{L}$ with fluoranthene, benzo(k)pyrene, benzo(b) fluoranthene, benzo(k)fluoranthene, benzo(ghi)perylene and indeno(1,2,3-cd)pyrene as reference compounds. Maximum levels for the sum of these PAHs in surface waters can reach $1 \mu \mathrm{g} / \mathrm{L}$, depending on the surface water treatment process.

Besides emission sources, PAH water concentrations depend also on the depth in the sediment core (see Table 5). It can be seen that a range of PAHs at varying concentrations were found in the porewater samples. Generally, it was the four-ring compounds that were found in the highest concentrations, the largest contribution to this arising from the compounds fluoranthene and pyrene. 
Table 5 PAH concentration (ng/L) in porewater samples from a sediment core from the Mersey Estuary (King et al. 2004)

\begin{tabular}{|c|c|c|c|c|c|c|c|c|}
\hline Depth $(\mathrm{cm})$ & Naphthalene & Acenaphthene & Flourene & Penanthrene & Anthracene & Flouranthene & Pyrene & $\sum$ PAHs \\
\hline $0-2.5$ & 67 & 75 & 26 & 58 & $<20$ & 77 & 106 & 409 \\
\hline $2.5-5$ & 275 & 43 & 29 & 44 & 42 & 62 & 109 & 604 \\
\hline $5-7.5$ & $<3$ & 46 & 17 & 17 & $<20$ & 28 & 58 & 166 \\
\hline $7.5-10$ & $<3$ & 66 & 105 & 126 & $<20$ & 100 & 125 & 522 \\
\hline $10-12.5$ & 27 & 21 & $<2$ & $<17$ & $<20$ & 14 & 32 & 95 \\
\hline $12.5-15$ & $<3$ & 16 & 28 & 45 & $<20$ & 85 & 86 & 260 \\
\hline $15-17.5$ & 62 & 16 & 33 & 45 & $<20$ & 75 & 92 & 323 \\
\hline $17.5-20$ & 33 & $<6$ & 10 & 12 & 57 & 15 & 32 & 159 \\
\hline $20-22.5$ & 19 & 20 & 6 & 7 & $<20$ & 13 & 32 & 96 \\
\hline $22.5-25$ & 65 & 23 & $<2$ & 12 & 50 & 15 & 33 & 198 \\
\hline $25-27.5$ & 29 & 19 & 32 & $<17$ & $<20$ & 111 & 275 & 467 \\
\hline $27.5-30$ & 69 & 71 & 52 & 94 & 85 & 162 & 189 & 721 \\
\hline $30-32.5$ & 41 & 20 & 7 & 9 & $<20$ & 18 & 34 & 129 \\
\hline $32.5-35$ & 35 & 16 & 6 & 10 & $<20$ & 17 & 31 & 116 \\
\hline $35-37.5$ & 30 & $<6$ & 7 & 15 & $<20$ & 19 & 36 & 107 \\
\hline $37.5-40$ & 54 & 20 & $<2$ & 6 & $<20$ & 15 & 30 & 126 \\
\hline $40-42.5$ & 107 & 49 & 35 & 76 & 71 & 181 & 220 & 739 \\
\hline $42.5-45$ & $<3$ & $<6$ & $<2$ & $<17$ & $<20$ & 73 & 83 & 156 \\
\hline $45-47.5$ & 159 & $<6$ & $<2$ & $<17$ & $<20$ & 37 & 38 & 234 \\
\hline $47.5-50$ & 65 & $<6$ & $<2$ & 7 & $<20$ & 26 & 31 & 129 \\
\hline $50-52.5$ & 268 & 78 & 29 & 74 & $<20$ & 130 & 162 & 742 \\
\hline $52.5-55$ & 103 & 47 & $<2$ & $<17$ & $<20$ & 100 & 162 & 353 \\
\hline
\end{tabular}

Naphthalene also dominated in many samples. Total PAH concentration in porewater varied widely with depth in the sediment core and several regions of high concentration can be recognised, the highest $(742 \mu \mathrm{g} / \mathrm{L})$ occurred at between 50 and $52.5 \mathrm{~cm}$ (King et al. 2004).

PAH in ambient and indoor air

The risk associated with human exposure to atmospheric PAHs is highest in cities, considering the density of population, increasing vehicular traffic, and scarce dispersion of the atmospheric pollutants (Rockens et al. 2000). Presently, limit values of 1 or $10 \mathrm{ng}$ benzo(a)pyrene per $\mathrm{m}^{3}$ air are recommended or mandatory in various countries (e.g. Italy or Germany). Actually, these concentrations are seldom found or exceeded nowadays in ambient air of rural or even of urban living areas (Jacob and Seidel 2002).

Based on calculated PAH diagnostic ratios, the major source of PAHs exposure was from vehicle exhaust (Liu et al. 2007; Zhu et al. 1997). In Taiwan region, several significant contributor to PAHs sources had been sampled such as stationary industrial combustion: steel and iron industries (Yang et al. 2002) with a mean total PAHs concentrations measured to be $1,020 \mu \mathrm{g} / \mathrm{m}^{3}$, traffic vehicles exhaust: motorcycle (Yang et al. 2005) and highway toll station (Tsai et al. 2004) with a mean total-PAHs con- centrations ranged from 8,280 to $12,300 \mathrm{ng} / \mathrm{m}^{3}$. Fang et al. (2004a, b, c) indicated that mean of total PAHs levels at industrial, urban, and rural areas in central Taiwan region ranged from 1,232 to $1,650,700$ to 1,740 , and 610 to $831 \mathrm{ng} / \mathrm{m}^{3}$, respectively. However, the $\mathrm{PM}_{2.5}$ (fine particulate) and $\mathrm{PM}_{2.5-10}$ (coarse particulate) total PAHs concentrations at the Tunghai University Pastureland (Taiwan) sampling site were found to be 180.62 and $164.98 \mathrm{ng} / \mathrm{m}^{3}$, respectively. In general, the concentrations of polycyclic aromatic hydrocarbons were higher in spring and winter than those of summer and autumn for either $\mathrm{PM}_{2.5}$ or $\mathrm{PM}_{2.5-10}$ in Taiwan (Fang et al. 2005). Table 6 showed the results of comparison of atmospheric PAHs concentrations in $\mathrm{PM}_{10}$ particulates with other studies around the world. In general, the results indicate that special sampling sites such as Taiwan urban, Taiwan traffic, Taiwan Petrochemical industrial, Flanders urban, Taichung pastureland and Taichung temple possess extremely high total PAHs average concentrations. When compared with the traffic, urban, petrochemical industrial, pastureland and temple sampling sites, Asian countries (Taiwan) have higher total PAHs concentrations than Europe (Italy and Belgium, except Urban Flanders, Belgium), South-East Asia (India and Malaysia) and America (Mexico) (Fang et al. 2006).

In general, summertime PAH levels tend a minimum, reflecting changes in prevailing meteorology, i.e. lower 
Table 6 Comparison of atmospheric PAHs concentrations $\left(\mathrm{ng} / \mathrm{m}^{3}\right)$ in $\mathrm{PM}_{10}$ particulates at different sites around the world (after Fang et al. 2006)

\begin{tabular}{|c|c|c|c|c|c|}
\hline Location & $\begin{array}{l}\text { Survey } \\
\text { year }\end{array}$ & $\begin{array}{l}\text { Total PAH's } \\
\text { concentrations }\end{array}$ & $\begin{array}{l}\mathrm{BaP} \\
\text { concentrations }\end{array}$ & Particle size & Literature \\
\hline Traffic, Tainan, Taiwan & 1994-1995 & 912 & 37.01 & $\mathrm{PM}_{10}\left(\sum 21 \mathrm{PAH}\right)$ & Sheu and Lee (1997) \\
\hline Urban, Tainan, Taiwan & 1994-1995 & 203.9 & 10.5 & $\mathrm{PM}_{10}\left(\sum 21 \mathrm{PAH}\right)$ & Sheu and Lee (1997) \\
\hline $\begin{array}{l}\text { Petrochemical industrial, Tainan, } \\
\text { Taiwan }\end{array}$ & 1994-1995 & 116.8 & 2.39 & $\mathrm{PM}_{10}\left(\sum 21 \mathrm{PAH}\right)$ & Sheu and Lee (1997) \\
\hline Residential, Naples, italy & 1996-1997 & 22.7 & 0.9 & $\mathrm{PM}_{10}\left(\sum 15 \mathrm{PAH}\right)$ & Caricchia et al. (1999) \\
\hline Traffic, Naples, italy & 1996-1997 & 54.8 & 2.97 & $\mathrm{PM}_{10}\left(\sum 15 \mathrm{PAH}\right)$ & Caricchia et al. (1999) \\
\hline Industrial, Naples, italy & 1996-1997 & 39.5 & 2.75 & $\mathrm{PM}_{10}\left(\sum 15 \mathrm{PAH}\right)$ & Caricchia et al. (1999) \\
\hline Urban, Mumbai, India & 1995 & 24.5 & 1.8 & $\mathrm{PM}_{10}\left(\sum 18 \mathrm{PAH}\right)$ & $\begin{array}{l}\text { Kulkarni and Venkatraman } \\
\quad(2000)\end{array}$ \\
\hline Industrial, Mumbai, India & 1995 & 38.8 & 2.1 & $\mathrm{PM}_{10}\left(\sum 18 \mathrm{PAH}\right)$ & $\begin{array}{l}\text { Kulkarni and Venkatraman } \\
\text { (2000) }\end{array}$ \\
\hline Urban, Kuala Lumpur, Malaysia & 1998-1999 & $6.3 \pm 4.4$ & - & $\mathrm{PM}_{10}\left(\sum 17 \mathrm{PAH}\right)$ & Omar et al. (2002) \\
\hline Rural, Kuala Lumpur, Malaysia & 2000 & $0.3 \pm 0.2$ & - & $\mathrm{PM}_{10}\left(\sum 17 \mathrm{PAH}\right)$ & Omar et al. (2002) \\
\hline Traffic, Hong Kong & $2000-2001$ & 44.54 & 2.13 & $\mathrm{PM}_{10}\left(\sum 16 \mathrm{PAH}\right)$ & Guo et al. (2003) \\
\hline Industrial, Hong Kong & $2000-2001$ & 23.86 & 1.3 & $\mathrm{PM}_{10}\left(\sum 16 \mathrm{PAH}\right)$ & Guo et al. (2003) \\
\hline Urban, Flanders, Belgium & $2000-2001$ & 93.025 & 0.82 & $\mathrm{PM}_{10}\left(\sum 16 \mathrm{PAH}\right)$ & Rockens et al. (2000) \\
\hline Industrial, Flanders, Belgium & $2000-2001$ & 55.125 & 0.76 & $\mathrm{PM}_{10}\left(\sum 16 \mathrm{PAH}\right)$ & Rockens et al. (2000) \\
\hline
\end{tabular}

inversions during winter, and lack of a major PAH source, residential fuel combustion for heating. It has been suggested that in urban areas only the particle associated with PAH were highest in winter, while the vapor phase compounds were highest in summer (Baek et al. 1991). However, in Brisbane the phenanthrene, fluorene and pyrene levels in both vapor and particle phase were highest in sample collected at lowest mean sampling temperature (Müller et al. 1998). Bodzek et. al. (1993) observed higher winter/summer ratios for particle-associated PAHs with a lower condensation degree (from fluorene to chrysene) and lower concentration ratios for the higher condensed PAHs $\mathrm{BFs}(\mathrm{B}(\mathrm{b}) \mathrm{Fl}+\mathrm{B}(\mathrm{k}) \mathrm{Fl}), \mathrm{B}(\mathrm{e}) \mathrm{Py}$ and $\mathrm{B}($ ghi)Pe. The authors attributed this difference to the temperature dependent distribution of the more volatile PAHs between the particle and the gaseous phase (Broman et al. 1991). Papageorgopoulou et al. (1999) PAHs were determined in the ambient air of six towns in Greece. Correlations of total $\mathrm{PAH}$ with other atmospheric pollutants were largely different among towns indicated that the relative contribution of emission sources is different in each location. In the warm months PAHs were significantly correlated with vehicular pollutants thus suggested traffic as major PAH emitting source. The same was also deduced from the comparison of the ambient PAH profiles to the profiles of particular sources. The contribution of residential heating was significant in most towns during winter. Principal component analysis of the data did not result in a clear distinction between towns suggested that all were influenced by similar source types.
Exposure of on-duty traffic police in Beijing to PAHs was investigated by Liu et al. (2007). The authors used a personal sampling technique in measuring both particulate and gaseous phase PAHs. The results were then compared with those from two control sites away from the street. Exposure levels to gaseous and particulate PAHs for the traffic police were found to be 1,525 \pm 759 and $148 \pm 118 \mathrm{ng} / \mathrm{m}^{3}$, respectively, representing 2-2.5 times higher levels than those at the control sites. However, Park et al. (2002) found negative correlation between vapor phase PAHs and temperature when investigating atmospheric PAHs in Seoul, Korea. It is believed that changes in the atmospheric mixing layer at higher temperatures leads to stronger convection and dilution, and Panshin and Hites (1994), Wania et al. (1998) even developed experimental equations to quantitatively describe the relationship between vapor PAHs and temperature.

The total concentration of 17 PAHs ranged between 0.84 and $152 \mathrm{ng} / \mathrm{m}^{3}$, with an average of $116 \mathrm{ng} / \mathrm{m}^{3}$, in urban area were 1.1-6.6 times higher than those measured in suburban area of Beijing (China). It suggested a serious pollution level of PAHs in Beijing. PAHs concentrations increased with decreasing the ambient temperature. Approximately $68.4-84.7 \%$ of PAHs were adsorbed on particles having aerodynamic diameter $62.0 \mu \mathrm{m}$. Coal combustion for domestic heating was probably major contributor to the higher PAHs loading in winter, whereas PAHs in other seasons displayed characteristic of mixed source of gasoline and diesel vehicle exhaust. Biomass burning and road dust are minor contributors to the PAHs 
composition of these aerosol particles. Except for source emission, other factors, such as meteorological condition, photochemical decay, and transportation from source to the receptor site, should to be involved in the generation of the observed patterns (Zhou et al. 2005).

Rehwagen et al. (2005) concluded that the results showed a PAH seasonal behaviour in both regions of $\mathrm{La}$ Plata (Italy), with lower contents in summer and higher ones in winter. Highest concentrations of total PAHs were found in the industrial area in La Plata. The size distribution of particles demonstrates the greater relevance of smaller particles. More than $50 \%$ of PAHs were associated with particles of less than $0.49 \mu \mathrm{m}$. Moreover, this particle size fraction was associated with traffic, whereas other sources of combustion were related also to particles between 0.49 and $0.95 \mu \mathrm{m}$. Considering the ratio of benzo(ghi)perylene /benzo(a)pyrene as an indicator for traffic influence, it was observed that La Plata City was more affected than Leipzig by the same proportion in summer and in winter. The benzo(g)perylene/indeno(123cd)pyrene ratio was lower in winter than in summer in both places and indicates the presence of domestic combustion sources. It is important to point out the significance of using fingerprint compound ratios to identify possible sources of pollution with PAHs bound to particles (Rehwagen et al. 2005).

In a similar study on exposure to airborne particles and PAHs close to a busy street in Gliwice (Poland). Bylina et al. (2005) found that the average concentration of PAHs near the street was more than 1.5 times greater than that $100 \mathrm{~m}$ away from the street. Although the total exposure was much lower than that observed in Beijing (only $192 \mathrm{ng} \mathrm{m}^{-3}$ in the spring), the results highlight the significant role exhaust gas emissions play in exposure to PAHs on busy streets (Liu et al. 2007).

For example, air concentrations of pyrene and of the sum of 12 PAH compounds measured indoors and outdoors in two kindergartens are presented in Table 7. The outdoor total PAH concentrations were 12 times higher in "polluted" kindergarten than in kindergarten situated in a "non polluted" area and 3 times lower than mean concentration measured near the highway in Montreal. On the contrary, no difference was found between the total PAH concentrations measured indoors in both kindergartens. Similar tendencies were observed for pyrene concentrations (Vyskocil et al. 2000).

Sharma et al. (2007) reported that concentrations of total PAHs in air were $667.73 \pm 399.38$ and $672.16 \pm$ $387.69 \mathrm{ng} / \mathrm{m}^{3}$ (Delhi, India) in the years 2002 and 2003, respectively. Data also reveal that the concentrations of PAHs are higher in the winter months than in the monsoon and summer months. In earlier studies also the concentrations of particle associated PAHs in urban areas have been found to peak in winter. The elevated concentrations of $\mathrm{PAH}$ in winter can be attributed to increased emissions from higher consumption of fossil fuels for heating purposes, more traffic volumes and less dispersion due to meteorological conditions prevailing in winter (Sharma et al. 2007).

Indoor air quality is of particular interest in the world. With the different functions and ventilation conditions, the concentrations of PAHs in indoor air were: bedroom $>$ kitchen $>$ living room $>$ balcony. Indoor air of kitchen is polluted by PAHs that come from not only outdoor air but also indoor emission sources such as cooking, gas home appliances (Liu et al. 2001). Except for cooking practice, cooking oil-fumes should make a significant contribution to PAHs concentrations of indoor air including two parts: (1) once heated PAHs evaporate from the polluted oil into air; (2) at high temperature organic compounds are partially cracked to smaller unstable fragments (pyrolysis), mostly radicals recombine to give relatively stable PAHs (pyrosynthesis) (Moret and Conte 2000).

Table 7 PAH concentrations in area (Vyskocil et al. 2000) ${ }^{\mathrm{a}}$

\begin{tabular}{|c|c|c|c|c|}
\hline \multirow[t]{2}{*}{ Place } & \multicolumn{2}{|c|}{ Total PAH ${ }^{\mathrm{b}}\left(\mathrm{ng} / \mathrm{m}^{3}\right)$} & \multicolumn{2}{|c|}{ Pyrene $\left(\mathrm{ng} / \mathrm{m}^{3}\right)$} \\
\hline & Outdoor & Indoor & Outdoor & Indoor \\
\hline Kindergarten in a polluted area & $36.1 ; 17.9 ; 14.8$ & $2.8 ; 2.6 ; 3.6$ & $5.1 ; 1.6 ; 1.3$ & $0.4 ; 0.3 ; 0.5$ \\
\hline Kindergarten in a nonpolluted area & $1.6 ; 2.2 ; 1.9$ & $1.0 ; 2.8 ; 2.5$ & $0.3 ; 0.4 ; 0.4$ & $0.2 ; 0.5 ; 0.5$ \\
\hline Montreal highway Décairie $(1989-1991)^{\mathrm{c}}$ & 62.7 & & & \\
\hline London $(1991)^{d}$ & 166 & & & \\
\hline \multicolumn{5}{|l|}{${ }^{\mathrm{a}}$ Individual values } \\
\hline \multicolumn{5}{|c|}{$\begin{array}{l}\text { b Total of } 12 \text { PAH: phenanthrene, anthracene, fluoranthene, pyrene, benzo(a)anthracene, chrysene, benzo(b)fluoranthene, benzo(k)fluoranthene, } \\
\text { benzo(a)pyrene, dibenzo(a,h)anthracene, benzo(ghi)perylene, indeno(1,2,3-c,d) pyrene }\end{array}$} \\
\hline
\end{tabular}


According to Zhu and Wang (2003) the average concentration of 12 PAHs in air of hotel and commercial kitchens of Hangzhou was $17 \mu \mathrm{g} / \mathrm{m}^{3}$, which comprised mainly of three- and four-ring PAHs. The corresponding average in domestic kitchens was $7.6 \mu \mathrm{g} / \mathrm{m}^{3}$ and consisted mainly of two- and three-ring PAHs. Anthracene was more abundant in domestic kitchen air than in commercial kitchen air. Food boiling produced the least amount of PAHs. The high-fat food produced more PAHs when broiled, so did low fat-level food when fried except pyrene and anthracene. In commercial kitchens, PAHs came from two sources, cooking practice and oil-fumes, however the cooking practice had a more predominant contribution to PAHs in commercial kitchen air. In domestic kitchens, except for cooking practice and oil-fumes, there were other PAHs sources, such as smoking and other human activities in the domestic houses, where three- to four-ring PAHs mainly came from cooking practice. Two-ring PAHs, naphthalene, was the most predominant kind, mostly resulting from the evaporation of mothball containing a large quantity of naphthalene, used to prevent clothes against moth. The level of air PAHs in commercial kitchens was very high. The exposure to $\mathrm{BaP}$ in domestic kitchens was $0.0044-0.016 \mu \mathrm{g} / \mathrm{day}$, while it increased to $0.32-0.94 \mu \mathrm{g} /$ day in commercial kitchens. Meanwhile, the production of PAHs from three common cooking oils was compared, in which lard produced more PAHs than rapeseed oil and soybean oil. An increase in cooking temperature generally increased the production of most PAHs.

The concentration ranges of individual PAH compounds along with their mean observed for indoor and outdoor locations are given in Table 8 (Pandit et al. 2001). The high concentrations observed for the lower molecular weight PAHs such as naphthalene and acenaphthylene in the indoor sample accounted for $58 \%$ of the total PAH while the same accounted for only $35 \%$ of the total PAH in outdoor samples. The outdoor samples were collected in an open area 5-6 $\mathrm{m}$ away from the respective houses. Indoor concentration levels of some of the compounds like nepthalene, phenanthrene and benzo(a)pyrene were found to be a magnitude higher than the respective outdoor levels. Except for anthracene $(\mathrm{I} / \mathrm{O}=0.8)$, the $\mathrm{I} / \mathrm{O}$ ratio of individual $\mathrm{PAH}$ compounds were always higher than one, varying from 1.6 to 10.5 . The concentration of the carcinogenic benzo(a)pyrene in the cooking environment using kerosene as fuel ranged between 0.2 and $17.6 \mathrm{ng} / \mathrm{m}^{3}$ and are found to be lower than $33-186 \mathrm{ng} / \mathrm{m}^{3}$ of benzo(a)pyrene from other cooking fuels like coal, wood and cattle dung as reported by Raiyani et al. (1993). Even then, it exceeds the air quality standard of $1 \mathrm{ng} / \mathrm{m}^{3}$ specified by a few countries (though not India) most of the time. The indoor concentration levels suggest that exposure to individual PAH compound during cooking period is 2-10 times higher than ambient exposure. However, based on 6$\mathrm{h}$ cooking and 18-h non-cooking periods, the average daily exposure was only two times higher than ambient air (Pandit et al. 2001).

Chiang et al. (1999) successfully identified four PAHs in fumes from these cooking oils (Chiang et al. 1999). $\mathrm{B}(\mathrm{a}) \mathrm{P}, \mathrm{DB}(\mathrm{ah}) \mathrm{A}$, and $\mathrm{B}(\mathrm{a}) \mathrm{A}$ are considered probable human carcinogens (group 2A); $\mathrm{B}(\mathrm{b}) \mathrm{FA}$ is considered a possible human carcinogens (group 2B) by IARC (1992). The carcinogenic contents $\left(\mu \mathrm{g} / \mathrm{m}^{3}\right)$ of fumes from various oils is shown in Table 9. Exposure to PAHs is considered

Table 8 Range and geometric mean concentrations $\left(\mathrm{ng} / \mathrm{m}^{3}\right)$ of PAH compounds in a kitchen using a kerosene stove (Pandit et al. 2001)

\begin{tabular}{|c|c|c|c|}
\hline Compound & Indoor (I) & Outdoor (O) & Mean $\mathrm{I} / \mathrm{O}^{\mathrm{a}}$ \\
\hline Naphthalene & ND-183.5 (67.2) & ND-16.6 (6.4) & 10.5 \\
\hline Acenapthylene & $2.6-45.1(28.8)$ & $0.6-16.5(6.5)$ & 4.3 \\
\hline Acenepthene & $4.6-22.6(14.1)$ & $4.6-18.2(8.9)$ & 1.6 \\
\hline Fluorene & ND-13.6 (4.6) & $0.7-2.2(1.2)$ & 3.8 \\
\hline Phenanthrene & ND-45.2 (10.3) & $1.0-2.2(1.4)$ & 7.3 \\
\hline Anthracene & ND-9.8 (2.3) & $2.3-3.0(2.8)$ & 0.8 \\
\hline Fluoranthene & $0.5-48.3(16.1)$ & $1.4-6.1(3.6)$ & 4.5 \\
\hline Pyrene & $1.4-45.5(12.8)$ & $2.0-7.8(4.5)$ & 2.8 \\
\hline Chrysene & $0.9-6.8(2.0)$ & $0.3-1.1(0.5)$ & 4.0 \\
\hline Benzo(a)anthracene & $1.1-9.7(2.9)$ & $0.4-1.6(0.8)$ & 3.6 \\
\hline Benzo(k)fluorenthene & $0.6-49.5(16.9)$ & $0.5-5.4(3.8)$ & 4.4 \\
\hline Benzo(a)Pyrene & ND-17.6 (6.9) & ND-2.0 (0.9) & 7.6 \\
\hline Total PAH & $25.3-373.9(164.2)$ & $23.0-45.6(36.7)$ & 4.5 \\
\hline
\end{tabular}

Mean concentrations are given in parentheses

$N D$ not detected

a The I/O ratio has been calculated from mean indoor concentration to mean outdoor concentration 
Table 9 The Carcinogenic Contents $\left(\mu \mathrm{g} / \mathrm{m}^{3}\right)$ of Fumes from various oils (Chiang et al. 1999)

\begin{tabular}{lrrr}
\hline Carcinogens & \multicolumn{3}{l}{ Cooking oil } \\
\cline { 2 - 4 } & \multicolumn{1}{l}{ Safflower } & Vegetable & \multicolumn{1}{c}{ Corn } \\
\hline BaP & $22.7 \pm 1.5$ & $21.6 \pm 1.3$ & $18.7 \pm 0.9$ \\
DBahA & $2.8 \pm 0.2$ & $3.2 \pm 0.1$ & $2.4 \pm 0.2$ \\
BbFA & $1.8 \pm 0.3$ & $2.6 \pm 0.2$ & $2.0 \pm 0.1$ \\
BaA & $2.5 \pm 0.1$ & $2.1 \pm 0.4$ & $1.9 \pm 0.1$ \\
\hline
\end{tabular}

$B(a) P \quad$ Benzo(a)pyrene, $\quad B(a) A \quad$ Benzo(a)fluoranthene, $\quad B(b) F A$ Benzo(b)fluoranthene, $B(g h i) P$ Dibenzo(ghi)perylene

an etiologic factor of lung cancer (Boffetta et al. 1997). Safflower oil, vegetable oil, and corn oil are frequently used by cooks in Taiwan and during the past 10 years. These results indicated that exposure to cooking oil fumes could possibly increase exposure to PAHs, which may be linked to the increased risk of lung cancer reported in Chinese Women. The concentration of $\mathrm{B}(\mathrm{a}) \mathrm{P}$ in cooking oil fumes exceeds that reported in cigarette smoke by a factor of 6.5 times (Guerrin 1993).

In general, a ratio of outdoor to indoor air PAH concentrations are about 2:1 in a room which is not polluted by tobacco smoking (Van Rooij et al. 1994). It must be, however, noted that the other prominent indoor combustion sources of PAH, such as heating and cooking were absent in kindergartens. Sakai et al. (2002) clearly demonstrated that cigarette smoking and meat cooking are the major emission sources of PAH in indoor air of the Tokyo area. It was also shown that PAH air pollution in the Tokyo area is serious both indoors and outdoors. Most large factories have already relocated to the outskirts of the Tokyo metropolitan area, since the Metropolitan government pollution control policies began in 1969 (TMG 1969). Thus, at present, motor vehicle exhaust is considered the largest emission source of PAH in the Tokyo metropolitan area. Average concentrations of $\mathrm{PM}_{10}$ and $\mathrm{PAH}$ in the air along the highway between Zurich and Basal on a fine summer afternoon were $55.0 \mu \mathrm{g} / \mathrm{m}^{3}$ and $127.5 \mathrm{ng} / \mathrm{m}^{3}$, respectively (Siegmann et al. 1999). Although this $\mathrm{PM}_{10}$ average is close to that in the suburban highway in the study, the PAH average is one half that of the suburban highway around Tokyo. Also, as the ventilation system was operating in Tokyo highway tunnels, it is speculated that the suburban and metropolitan highways in the Tokyo area are much more polluted by PAH. On this account, it was disclosed that a recent increase in the number of motor vehicles in Tokyo (TMG 2000; JEA 2000) has resulted in a serious increase in the outdoor concentrations of PAH there.

Gas and particle-phase pollutant emission was measured in the Caldecott Tunnel in the San Francisco Bay Area in the summer of 1996. Diesel trucks were the major source of lighter $\mathrm{PAH}$, whereas light-duty gasoline vehicles were the dominant source of higher molecular weight PAH. Sizeresolved measurements of particulate PAH showed significant fractions of diesel derived PAH to be present in both the ultra-fine size mode $(<0.12 \mu \mathrm{m})$ and the accumulation mode $(0.12-2 \mu \mathrm{m})$. In contrast, the gasoline engine-derived PAH emissions were found almost entirely in the ultra-fine mode (Miguel et al. 1998).

\section{Soil}

Soil system seems to be the important long-term repository for PAHs and is considered to be a steady indicator of the environmental pollution state. Accumulation of PAHs in soils may lead to further potential contamination of vegetables and food chains (Kipopoulou et al. 1999; Mueller and Shann 2006), and then cause direct or indirect exposure to human. Moreover, leaching, evaporation and migration are possible PAHs sources of atmospheric or groundwater contamination. Therefore, knowledge of soil contamination with PAHs is needed to avoid any food production risk and to restrict the deleterious effect of these contaminants. Sorption and degradation are key processes that affect the fate and transport of PAHs in the environment (Magee et al. 1991). Sorption also plays a key role in controlling transport of PAHs during leaching, as well as in transformation and bio-accumulation processes (Reeves et al. 2004). For example, Amellal et al. (2006a) studied the sorption and desorption of ${ }^{14} \mathrm{C}$-labelled phenanthrene on soils, during 6 months of natural conditions. The results showed that phenanthrene was strongly adsorbed and poorly desorbed. Consequently, in the leachates of microlysimeters, phenanthrene represented only a limited proportion, from 20 to $40 \%$. Leaching primarily concerned degradation products, maybe including traces of 9,10phenanthrenedione, which was present in significant quantities in the soils in an extractable state. Lastly, the sequestration or formation of non-extractable residues can contribute in a very significant and quasi-final way to the exclusion of the pollutant from any other process which defines its behaviour in the soil. Amellal et al. (2006b) observed that when biological degradation occurs, there was an increased in sequestration and in leaching, as well as in the concentration in residues in pore water. The increased in availability for leaching was exclusively due to the formation of degradation products that were more soluble and/or less adsorbed than phenanthrene on the surface of the aggregates. In the same way, these compounds were responsible for the increased in the concentration in residues observed in the immobile water of the soil. The passage of phenanthrene degradation products into soil pore water occurs by diffusion due to the effect of 
a concentration gradient created by the degradation of phenanthrene (and the formation of degradation products) on the surface of the aggregates where it was initially adsorbed. In addition, this diffusion facilitates the sequestration of the compounds in the soil. They concluded that in soils contaminated by strongly adsorbed organic compounds, water pollution and sequestration are primarily controlled by degradation.

Many studies have been reported for the PAHs in soils in some countries (Wild et al. 1990; Weiz et al. 1994; Nam et al. 2003). It was reported that the typical endogenous PAHs in soils are in the range of $1-10 \mu \mathrm{g} / \mathrm{kg}$ (Edwards 1983), and most of them are derived from oil seeps, bitumens, coal, plant debris, forest and prairie fires (Yunker et al. 2002). PAHs with three rings or more tend to be very strongly adsorbed to the soil matrices (Knox et al. 1993), preferentially to small aggregates $(<50 \mu \mathrm{m})$, which also contain the most humified organic matter (Quantin et al. 2005). Strong adsorption coupled with very low water solubility render PAH loss by leaching insignificant. Lichtfouse et al. (1997) reported that soil PAHs were mainly of pyrolytic origin, e.g. exogenous (airborne) contributions of fossil fuel combustion products and (old) vegetation fires, with a small contribution of uncombusted fossil fuels.

A number of studies have shown that PAHs adsorb very strongly to the surface of soil particles and organic matter, and are hence not readily available for biodegradation. For example, Fu et al. (1994) observed that $30 \pm 50 \%$ of naphthalene, the most water-soluble and bioavailable $\mathrm{PAH}$, resisted desorption from an Oklahoma soil consisting of $92 \%$ sand.

According to Vyskocil et al. (2000) the total PAH concentration in the soil from the kindergarten situated in the "polluted" area was twice higher than that in the "non-polluted" area (see Table 10).

The highest concentration of PAHs was detected in the chemical area of Tarragona (476.2 ng/g), with values two- and four-times higher than those of the urban/ residential (206.9 ng/g) and the petrochemical zones (119.7 ng/g), respectively. Finally, the lowest concentration

Table 10 PAH concentrations in soil (Vyskocil et al. 2000)

\begin{tabular}{lcc}
\hline Place & $\begin{array}{l}\text { Total } \mathrm{PAH}^{\mathrm{a}} \\
(\mathrm{ng} / \mathrm{g})\end{array}$ & $\begin{array}{l}\text { Pyrene } \\
(\mathrm{ng} / \mathrm{g})\end{array}$ \\
\hline Kindergarten in a polluted area & 132 & 10.4 \\
Kindergarten in a non polluted area & 65 & 6.1 \\
\hline
\end{tabular}

a Total of 12 PAH: phenanthrene, anthracene, fluoranthene, pyrene, benzo(a)anthracene, chrysene, benzo(b)fluoranthene, benzo(k)fluoranthene, benzo(a)pyrene, dibenzo(a,h)anthracene, benzo(ghi)perylene, indeno( $1,2,3-\mathrm{c}, \mathrm{d})$ pyrene corresponded to soils sampled in the unpolluted area $(52.8 \mathrm{ng} / \mathrm{g})$. Notwithstanding, the differences did not reach the level of statistical significance, for any of the individual PAHs, as well as for the sum of 16 PAHs and the sum of 7 carcinogenic PAHs. With respect to the total PAH sum, the concentration in soil samples from the chemical and urban areas decreased, while the levels corresponding to the petrochemical and unpolluted zones increased. Excepting those samples collected in the Southern complex, a similar tendency was noted for the levels of seven carcinogenic PAHs. However, the temporal variation was not statistically significant for any of both groups of organic pollutants here analyzed. When the hydrocarbons were individually assessed, it was found that the concentration of naphthalene increased significantly from 5.3 to $24.4 \mathrm{ng} / \mathrm{g}(p<0.05)$ and from 3.7 to $16.6 \mathrm{ng} / \mathrm{g}$ $(p<0.001)$ in the chemical and petrochemical areas, respectively. In contrast, acenaphthylene levels significantly decreased in urban samples (from 23.4 to $3.0 \mathrm{ng} / \mathrm{g}$, $p<0.01$ ), while no significant changes were found for the remaining PAHs (Nadal et al. 2007).

Wilcke and Amelung (2000) reported that the total of 20 PAHs in the soils from North America Great Plain ranges from 60 to $180 \mu \mathrm{g} / \mathrm{kg}$, while PAHs in the vegetable soils in Guangzhou (China) is higher than this range (Chen et al. 2005).

In another work PAH were present in the $0-10 \mathrm{~cm}$ soil from the Swiss soil monitoring network (NABO) observation sites in concentrations from 50 to $619 \mu \mathrm{g} / \mathrm{kg} \mathrm{dw}$. The highest concentrations were observed in urban areas (400-619 $\mu \mathrm{g} / \mathrm{kg} \mathrm{dw}$ ), irrespective of the land utilization type (city park, forests, arable land). In rural areas, concentrations of $16 \mathrm{PAH}$ in arable soils ranged from 60 to $145 \mu \mathrm{g} / \mathrm{kg} \mathrm{dw}$, in permanent and pasture grassland soils from 50 to $314 \mu \mathrm{g} / \mathrm{kg} \mathrm{dw}$, and in forest soils from 98 to $219 \mu \mathrm{g} / \mathrm{kg} \mathrm{dw}$. Median values obtained in these main compartments increased in the order of arable soils $(66 \mu \mathrm{g} /$ $\mathrm{kg} \mathrm{dw})<$ permanent and pasture grassland $(142 \mu \mathrm{g} / \mathrm{kg}$ $\mathrm{dw})<$ forests $(164 \mu \mathrm{g} / \mathrm{kg} \mathrm{dw})<$ urban soils $(451 \mu \mathrm{g} / \mathrm{kg}$ dw) (Bucheli et al. 2004). However, Capuano et al. (2005) reported that the values of $\mathrm{PAH}$ decrease with depth soil, for example, for sample 1 total PAH concentrations were $318,9 \mu \mathrm{g} / \mathrm{kg} \mathrm{dw}(10 \mathrm{~cm}), 88,9 \mu \mathrm{g} / \mathrm{kg} \mathrm{dw}(20 \mathrm{~cm})$ and $74,1 \mu \mathrm{g} / \mathrm{kg} \mathrm{dw}(30 \mathrm{~cm})$. The PAH-concentrations in soil samples from site 1 are approximately two orders of magnitude higher than those in other soils in the vicinity of human activities (see Table 11).

According to Masih and Taneja (2006) the average concentration of total PAH in all samples (Agra-semiarid region of India) was $12.1 \mu \mathrm{g} / \mathrm{g}$ and the range was from 3.1 to $28.5 \mu \mathrm{g} / \mathrm{g}$. The total PAH concentrations were 13.72 , $12.98,9.37$ and $6.73 \mu \mathrm{g} / \mathrm{g}$ at industrial, roadside, residential and agricultural sites, respectively. The industrial sites had 
Table 11 Total concentrations of PAHs in soils ( $\mu \mathrm{g} g$ dry wt.) in urban areas and in the vicinity of human (industrial) activities (after Bakker et al. 2000)

\begin{tabular}{lllll}
\hline Location & $\begin{array}{l}\text { Number } \\
\text { of PAHS }\end{array}$ & Soil depth $(\mathrm{cm})$ & $\begin{array}{l}\text { PPAH concentration } \\
\text { in soil }(\mu \mathrm{g} \text { g dry wt.) }\end{array}$ & Reference \\
\hline Highway (CAN) & 17 & Surface & 1.4 & Wang and Meresz (1982) \\
Motorway (UK) & 7 & $0-4$ & 20 at $1 \mathrm{~m}$ & Butler et al. (1984) \\
Highway (USA) & 14 & $0-8$ at $600 \mathrm{~m}$ & Yang et al. (1991) \\
Urban (JAP) & 8 & $0-3$ & 3 & Spitzer and Kuwatsuka (1993) \\
Chemical plant (AUS) & 18 & $0-5$ & $1.3 \pm 0.8$ & Weiss et al. (1994) \\
Urban (CH) & 16 & $0-20$ & $0.3-79$ & Niederer et al. (1995) \\
Al plant (SK) & 17 & Surface & $11-12$ & Wickle et al. (1996) \\
Urban (UK) & 16 & $0-10$ & $40-200$ & Meharge et al. (1998) \\
Polyprop. fire (UK) & 16 & $0-10$ & $2.7 \pm 0.5$ & $12-18$ \\
\hline
\end{tabular}

${ }^{a}$ Organic surface layer

the highest total PAH concentration followed by roadside, residential and agricultural site. High concentrations at industrial site can be due to the location of the site, which is well known for generator manufacturing, tanning and iron casting industries. The maximum concentrations of PAHs were found to be in winter season. The concentration of PAH decreased in the order chrysene $>$ benzo(b)fluoranthene $>$ fluoranthene (Masih and Taneja 2006). This might be due to industrial-oil burning, wood combustion and emission coming from diesel powered vehicles (Ravindra et al. 2001).

The total PAHs concentrations in soils from the paddy fields at Hunpu wastewater irrigation areas in Shenyang, China, were between 950 and $2,790 \mu \mathrm{g} / \mathrm{kg}$. There was no regular pattern on the accumulation of PAHs in soil along the irrigation channel from the upper reach to the lower reach. For instance, total PAHs measured in soil at sites 1 and 2 were 2,760 and $2,000 \mu \mathrm{g} / \mathrm{kg}$, respectively, but the content of total PAHs was $2,230 \mu \mathrm{g} / \mathrm{kg}$ in soil at site 6 about $25 \mathrm{~km}$ further downstream from site 1, which suggested that the channel played no role in the dilution and decontamination of the pollutants. Two reasons contributed to this phenomenon: one was the re-solubilizing of pollutants from the channel sediment, former study (Song et al. 2005) had showed that the total content of 16 PAHs in the channel sediment had reached up to $67 \mathrm{mg} / \mathrm{kg}$; the other might be the possible additional unregulated discharge of sewages in the middle and/or lower reach of the channel, both of which would result in the elevated accumulation of pollutants in soils at the sites far from the pollution sources of the upper reach. This was consistent with communications with local farmers at the sampling sites. The total concentration of the 14 PAHs in soil collected from the wastewater irrigation region in the former eastern Berlin, ranged from 830 to $3,690 \mu \mathrm{g} / \mathrm{kg}$; there were no significant differences between residual total PAHs for samples from adjacent sites (Song et al. 2006). For comparison, Chen et al. (2003) reported that the total PAHs were 3,000$5,000 \mu \mathrm{g} / \mathrm{kg}$ in the agricultural soil within the wastewater irrigation region in Tianjin, China. The background level of TPAHs in the unpolluted paddy soil in Shenyang, China, was $275-317 \mu \mathrm{g} / \mathrm{kg}$ (Song et al. 2002).

PAH contents ranged from $450 \mu \mathrm{g} / \mathrm{kg}$ of dry material at Honfleur to $5,650 \mu \mathrm{g} / \mathrm{kg}$ at Notre-Dame de Gravenchon (France) (Motelay-Massei et al. 2004). MaliszewskaKordybach (1996) measured an average of $264 \mu \mathrm{g} / \mathrm{kg}$ (for 16 PAHs) in agricultural soils in Poland.

Aamot et al. (1996) found low values $(144 \mu \mathrm{g} / \mathrm{kg}$ on average) in forested soils of Norway. However, in Estonian urbanized areas, the high levels reported were from 2,200 to $12,300 \mu \mathrm{g} / \mathrm{kg}$ (Trapido 1999). Mielke et al. (2001) found concentrations of $3,700 \mu \mathrm{g} / \mathrm{kg}$ in the urban centre of New Orleans (USA). The concentration range of 16 PAHs varied by over two orders of magnitude from $0.016 \mu \mathrm{g} / \mathrm{kg}$ in rural to $3.884 \mu \mathrm{g} / \mathrm{kg}$ in suburban soils of Beijing (China) (Ma et al. 2005). The concentrations of the total PAH at rural site were generally less than those of urban site of Tianjin, China. Total PAH concentrations ranged from 144 to $308 \mathrm{ng} / \mathrm{m}^{3}$ and 239 to $537 \mathrm{ng} / \mathrm{m}^{3}$ for Chenlou and Meteorological tower sampling, respectively $(\mathrm{Wu}$ et al. 2006). The total PAH at meteorological tower (urban) were about one or two order higher than those of Mumbai (21$42 \mathrm{ng} / \mathrm{m}^{3}$; Venkataraman et al. 1999) and Kuala Lumpur $\left(6.28 \pm 4.35 \mathrm{ng} / \mathrm{m}^{3}\right.$; Omar et al. 2002), and were close to the concentration of Inchon (410 ng/m $\mathrm{m}^{3}$; Bae et al. 2002) in winter season. The average total $\mathrm{PAH}$ at Chenlou was also much higher than that of Yangsuri rural $\left(119 \mathrm{ng} / \mathrm{m}^{3}\right.$; Bae et al. 2002). The total PAH differences between Chenlou (rural) and meteorological tower (urban) were significant and similar results have been reported in Massachusetts 
(Allen et al. 1996), Kuala Lumpur (Omar et al. 2002), Birmingham (Smith and Harrison 1996) and Korea (Bae et al. 2002) with the urban and rural total PAH were 49.5, $6.28,4.37,410$ and $1.94,1.3,1.13,119 \mathrm{ng} / \mathrm{m}^{3}$, respectively.

Crépineau et al. (2003) reported a study on the contamination of pastures, grass and soil samples by PAHs in the vicinity of a highway (70,000 vehicles per day). All samples have been collected from $10 \mathrm{~m}(\mathrm{~d} 1), 50 \mathrm{~m}(\mathrm{~d} 2)$, and $150 \mathrm{~m} \mathrm{(d3)}$ perpendicular to a French highway and at a control site in a rural area away from nearby contaminating sources. Total PAH concentration were ranges from $767 \mathrm{ng} / \mathrm{g}$ dry weight to $3,989 \mathrm{ng} / \mathrm{g}$ dry weight, according to the matrix and the distance from the highway. The authors concluded that the distance was not a significant factor for $\mathrm{PAH}$ deposition on grass, while in soil it has an effect between $\mathrm{d} 1$ and $\mathrm{d} 2$ or $\mathrm{d} 3$. The total PAH concentration in highway samples was eight times higher than in control site samples for grass and seven to four times higher for soil. Fluoranthene, pyrene, and phenanthrene were the major PAHs in grass samples at the control site and the highway, but the concentrations were about five times higher near the highway. In soil samples collected near the highway, the values of concentrations between all compounds were not statistically different. PAH deposition on grass was linked to the physicochemical properties of the compounds, which lead to a specific distribution of each molecule (according to their volatility and the number of aromatic rings) while no specific behavior was revealed in soil. In another work (Bryselbout et al. 2000) results showed that the lowmolecular weight PAHs such as naphthalene, fluorene, and anthracene increased from 2 to $6 \mathrm{~m}$ of a highway (Nancy, France). However, the concentrations of highmolecular weight PAHs such as benzo(a)pyrene and benzo(g,h,i)pyrene decreased from 2 to $6 \mathrm{~m}$. According to these authors the results strengthen the hypothesis of a local distillation effects around the highway.

Table 12 shows a worldwide comparison of PAHs concentration (Masih and Taneja 2006). The PAH concentration in soil of industrial $(13.72 \mu \mathrm{g} / \mathrm{g})$ and roadside $(12.98 \mu \mathrm{g} / \mathrm{g})$ area of Agra is less than the concentration found in Austria/Germany $(79.00 / 16.00 \mu \mathrm{g} / \mathrm{g})$ and USA $(58.60 \mu \mathrm{g} / \mathrm{g})$, respectively, whereas residential $(9.37 \mu \mathrm{g} / \mathrm{g})$ and agricultural $(6.73 \mu \mathrm{g} / \mathrm{g})$ sites concentrations of $\mathrm{PAH}$ were found to be higher than in UK $(4.20 \mu \mathrm{g} / \mathrm{g})$ and Germany $(1.90 \mu \mathrm{g} / \mathrm{g})$, respectively. As evident from the Table 12 the concentrations measured in soils of various sites at Agra (industrial, roadside, residential and agricultural) show much difference between each other. In the present data, contamination in the urban industrial area appears to be two times higher than in agricultural areas; similar results have been reported in earlier studies (Tremolada et al. 1996; Wagrowski and Hites 1997).
Table 12 Soil PAH

concentrations compiled from literature data (after Masih and Taneja 2006)

\begin{tabular}{llll}
\hline Study area & $\begin{array}{l}\text { PAH } \\
\text { concentration }(\mu \mathrm{g} / \mathrm{g})\end{array}$ & $\begin{array}{l}\text { Number } \\
\text { of PAH }\end{array}$ & Reference \\
\hline $\begin{array}{l}\text { Agricultural (rural) } \\
\text { Brazil }\end{array}$ & 0.096 & & \\
UK & 0.19 & 20 & Wickle et al. (1999) \\
Germany & 1.90 & 06 & Wild and Jones (1995) \\
India & 6.7 & 11 & Tebaay et al. (1993) \\
Residential (urban) & & & Masih and Taneja (2006) \\
Bangkok & 0.38 & 20 & Wickle and Muller (1999) \\
Brazil & 0.39 & 20 & Wickle et al. (1999) \\
Germany & 1.80 & 06 & Tebaay et al. (1993) \\
UK & 4.20 & 12 & Wild and Jones (1995) \\
India & 9.3 & 11 & Masih and Taneja (2006) \\
Roadside (urban) & & & \\
Australia & 3.30 & 14 & Yang et al. \\
USA & 58.68 & 14 & Rogge et al. (1993) \\
India & 12.9 & 14 & Masih and Taneja (2006) \\
Industrial (urban) & & & \\
UK & 4.50 & 12 & Wild and Jones (1995) \\
Germany & 16.0 & 06 & Tebaay et al. (1993) \\
Austria & 79.0 & 18 & Weiss et al. (1994) \\
India & 13.7 & 11 & Masih and Taneja (2006) \\
\hline
\end{tabular}




\section{Sediments}

Sediments are deposited material consisting of organic matter in various stages of decomposition, particulate mineral matter and inorganic material of biogenic origin. They have been proven an efficient tool to identify environmental impacts (Evans et al. 1990). Due to the exposure time to industrial effluents, they are valid for long-term studies. Sediments constitute a pollutant trap and are an important factor to establish the assimilative capacity of the environment. Sediments may contain a high level of pollutants ready to pass on to the food chain or be mobilised by anthropogenic or natural means. Therefore, sediments can act as indicator of the relationship between natural and anthropogenic variables (Salomons 1995; Calmano et al. 1996).

PAHs entering the aquatic environment, due to their hydrophobicity, rapidly become associated with sediments and suspended particles. Sediment retention capacity may be related to physico-chemical properties such as grain size and organic matter. Previous results have demonstrated that the sorption of hydrocarbons is related to the organic matter of the sediments.

According to Viguri et al. (2002) the results of the distribution of PAHs in surface sediments of the Santander Bay, Cantabric Sea, (Spain), the concentration of PAHs were strongly dependent on the organic matter, with sediments below $2 \%$ of organic matter always below $10 \mu \mathrm{g}$ $\Sigma 16 \mathrm{PAHs} / \mathrm{g} \mathrm{dw}$. The left side of the Bay, where the main urban and industrial activities take place, shows sediment samples with very high concentrations $(355 \mu \mathrm{g} / \mathrm{g} \mathrm{dw})$ of the sum of the 16 PAHs. An important change in the sediments characterisation can be observed according to the industrial activities along the rivers in the estuaries. From heavily polluted sediments in the Boo estuary, moderately polluted sediments in the Solia and San Salvador estuary to slightly/non-polluted sediments in the Cubas estuary. This result allows us to consider that important changes in the PAHs accumulation in sediments take place depending on the direct influence of anthropogenic activities, mainly combustion processes of traffic and industrial activities.

\section{Occupational exposure}

An increased risk of cancer has been reported in occupations with heavy exposure to traffic related air pollution, such as professional drivers. PAHs are present in gasoline and diesel engine exhaust, thus making, motor vehicle emissions in urban areas a major source of exposure to these compounds (Fromme et al. 1998). Personal PAH exposure due to urban traffic has been the subject of several investigations, be it in the general population (Minoia et al. 1997) or in occupationally exposed individuals, such as policemen (Merlo et al. 1997; Perico et al. 2001) and newsagents (Piccardo et al. 2003). Menichini (1992) reported that the evaluate the daily personal exposure to benzo(a)pyrene is one of the most important of taxi drivers. Twenty-four hour personal exposures (both occupational and environmental) to benzo(a)pyrene of 15 taxi drivers working in Genoa was determined by Piccardo et al. (2004). Daily personal B(a)P exposures of taxi drivers and controls in Genoa and mean daily airborne B(a)P concentrations $\left(\mathrm{ng} / \mathrm{m}^{3}\right)$ measured by three fixed samplers in different monitoring periods shown in Table 13. Table 13 also reports the daily $\mathrm{BaP}$ concentrations measured by three fixed $\mathrm{PM}_{10}$ monitoring stations during the same periods of personal exposure sampling. The mean $\mathrm{BaP}$ exposures measured at these different times were 1.4, 1.23 and $1.22 \mathrm{ng} / \mathrm{m}^{3}$, respectively, values were significantly greater than the levels found in controls $(0.16 \pm 0.2 \mathrm{ng} /$ $\mathrm{m}^{3}$ ). Mean daily personal $\mathrm{B}(\mathrm{a}) \mathrm{P}$ exposures of taxi drivers were not statistically different from the mean daily airborne $\mathrm{B}(\mathrm{a}) \mathrm{P}$ concentrations measured by fixed samplers during the same sampling periods. However, they concluded that
Table 13 Daily personal BaP exposures of taxi drivers and controls in Genoa and mean daily airborne $\mathrm{BaP}$ concentrations $\left(\mathrm{ng} / \mathrm{m}^{3}\right)$ measured by three fixed samplers in different monitoring periods (after Piccardo et al. 2004)

\begin{tabular}{lcclll}
\hline & No. samples & Mean \pm SD & Geometric mean & Min & Max \\
\hline $\begin{array}{l}\text { Personal exposure of taxi drivers } \\
\text { May-July 1998 }\end{array}$ & 15 & $1.04 \pm 0.66$ & 0.85 & & \\
February 1999 & 7 & $1.23 \pm 0.50$ & 1.16 & 0.17 & 2.66 \\
June 1999 & 7 & $1.22 \pm 1.10$ & 0.84 & 0.72 & 2.27 \\
Personal exposure of controls & 5 & $0.16 \pm 0.12$ & 0.11 & 0.22 & 2.82 \\
April 1999 & 5 & & & \\
Fixed sampling stations & & & & \\
May-July 1998 & 13 & $1.05 \pm 0.5$ & 0.78 & 0.28 \\
February 1999 & 5 & $1.52 \pm 0.6$ & 1.44 & 0.95 & 2.4 \\
June 1999 & 4 & $1.16 \pm 0.2$ & 1.15 & 1.0 & 1.4 \\
April 1999 & 3 & $1.17 \pm 0.4$ & 1.12 & 0.8 & 1.6 \\
\hline
\end{tabular}


mean daily $\mathrm{B}(\mathrm{a}) \mathrm{P}$ exposures measured in taxi drivers during May-June $1998,\left(n=9 ; 1.19 \pm 0.7 \mathrm{ng} / \mathrm{m}^{3}\right)$ were significantly higher $(P-0.01)$ than the daily $\mathrm{BaP}$ exposures measured during the same sampling months in another occupational category, namely non-smoker newsagents $\left(n=16 ; \quad 0.65 \pm 0.25 \mathrm{ng} / \mathrm{m}^{3}\right) \quad$ (Piccardo et al. 2003). Newsagents work $12 \mathrm{~h}$ shifts a day inside open newsstands commonly placed in heavily trafficked areas. Therefore, their lower mean $\mathrm{BaP}$ exposure would seem to confirm the importance of pollution levels usually found inside vehicles. Indeed, in Berlin Fromme et al. (1998) sampled B(a)P in the interior of a car in the breathing zone of passengers for $9 \mathrm{~h}$ (from 07:00 to 16:00 $\mathrm{h}$ under different meteorologic conditions). The mean values obtained during the two measurement periods (summer and winter) inside the car were 1.0 and $3.2 \mathrm{ng} / \mathrm{m}^{3}$ for benzo(a)pyrene, 10.2 and $28.7 \mathrm{ng} / \mathrm{m}^{3}$ for total-measured-PAHs, and in the subway 0.7 and $4.0 \mathrm{ng} / \mathrm{m}^{3}$ for benzo(a)pyrene, 30.2 and $67.5 \mathrm{ng} / \mathrm{m}^{3}$ for total PAHs. A comparison between subway and car exposures shows significantly higher concentration of PAHs in the subway train, which can be explained by relatively high concentrations of fluoranthene and pyrene in the subway. So far a satisfactory explanation has not been found, but one source might be the wooden railway ties which were formerly preserved with tar based products. In wintertime in both transportation systems the concentrations of benzo(a)pyrene are three to four times higher than in summer corresponding to the changing of the ambient air concentrations.

Mielke et al. (2004) were determined PAH concentrations of the inner-city and suburban census tracts. Table 14 list the results of the medians of each local site by percentiles. The largest medians are found along busy streets and the ranking for the remaining sites are foundations $>$ residential streets $>$ open areas of New Orleans. Note that the same overall trend exists for both PAHs and metals. The most pronounced trend is for PAHs. Busy streets have over twice the quantities of PAHs as foundation soils, the second largest PAH containing soil. Vehicle exhaust is the major source PAHs in residential communities. Note that as traffic volumes change from busy streets to residential streets, the amount of PAHs also changes in the direction expected (Mielke et al. 2004).

From the huge number of studies on the PAH exposure at workplaces a small selection is collated in Table 15 . which presents concentration of benzo(a)pyrene only. It shows that there are enormous variations even at similar or identical workplaces, but also that significant progress has been made by modernisation of the plants to reduce the emission of PAH (Jacob and Seidel 2002). This holds in particular for coke plants for which the limit values have been set to $5 \mathrm{mg} \mathrm{B}(\mathrm{a}) \mathrm{P} / \mathrm{m}^{3}$ for the oven platform and to $2 \mathrm{mg} \mathrm{B}(\mathrm{a}) \mathrm{P} / \mathrm{m}^{3}$ for other workplaces in Germany
Table 14 Median PAH concentrations stratified by residential collection sites for the combined data of the inner-city and suburban census tracts (Mielke et al. 2004)

\begin{tabular}{lrrrr}
\hline PAH & $\begin{array}{c}\text { Busy } \\
\text { streets }\end{array}$ & $\begin{array}{l}\text { Residential } \\
\text { streets }\end{array}$ & $\begin{array}{c}\text { Open } \\
\text { areas }\end{array}$ & $\begin{array}{c}\text { Foundation } \\
\text { samples }\end{array}$ \\
\hline A & 10 & 8 & 2 & 8 \\
B & 6 & 0 & 5 & 9 \\
C & 1 & 4 & 4 & 5 \\
D & 1 & 0 & 3 & 3 \\
E & 133 & 29 & 21 & 77 \\
F & 38 & 8 & 7 & 10 \\
G & 266 & 107 & 82 & 105 \\
H & 237 & 97 & 67 & 78 \\
I & 145 & 41 & 28 & 51 \\
J & 111 & 42 & 32 & 40 \\
K & 319 & 112 & 94 & 105 \\
L & 95 & 34 & 24 & 72 \\
M & 255 & 141 & 144 & 163 \\
N & 322 & 202 & 205 & 233 \\
O & 208 & 126 & 123 & 128 \\
P & 237 & 125 & 122 & 137 \\
PAH & 2,469 & 1,061 & 975 & 1,188 \\
$N$ & 8 & 18 & 6 & 6 \\
\hline rats & & 18 &
\end{tabular}

Units are ng/g. Key for polycyclic aromatic hydrocarbons: A, naphthalene; B, aenaphthylene; C, acenaphthene; D, fluorene; E, phenanthrene; F, anthracene; G, fluroanthene; H, pyrene; I, benz(a) anthracene; J, chrysene; K, benzo(b)fluoranthene; L, benzo(k)fluoranthene; $\mathrm{M}$, benzo(a)pyrene; $\mathrm{N}$, indeno[1,3,3-cd]pyrene; $\mathrm{O}$, dibenz (a,h)anthracene; P, benzo(g,h,i)perylene; total PAHs

(TRK-Wert 1989), Poland (Srogi 2007) and $0.15 \mathrm{mg}$ $\mathrm{B}(\mathrm{a}) \mathrm{P} / \mathrm{m}^{3}$ in France for the production of coke electrodes (Jacob and Seidel 2002).

It should be noted that, industrial contamination of workers of PAH has been found to occur by disposition from air or following contact with contaminated surfaces including clothing and tools. The studies indicate that total PAH in skin oil of roofing workers and road-paving crews may reach levels as high as $1,400 \mathrm{ng} / \mathrm{cm}^{2}$ (Jongeneelen et al. 1988). Of concern in such individuals, PAH are highly lipophillic compounds and thus are readily absorbed through the skin (Van Rooij et al. 1993).

\section{1-Hydroxypyrene—-biological monitoring}

The assessment of environmental exposure to PAH requires the measurement of levels present in each pathway of possible contact. The biological monitoring of PAH enables the best way to assess the internal dose of PAH.

1-Hydroxypyrene in human urine has been examined as a potential biomarker for the assessment of human exposure to PAHs (Viau et al. 1995). In general, background 
Table 15 Benzo[a]pyrene concentration at various workplaces

\footnotetext{
a 20 cigarettes/day

b Non-smoking

c 15 cigarettes/day

${ }^{\text {d }}$ In 1994
}

\begin{tabular}{|c|c|c|c|}
\hline Workplace & Country & Benzo(a)piren $\left(\mu \mathrm{g} / \mathrm{m}^{3}\right)$ & References \\
\hline Coke plants & Poland & & $\begin{array}{l}\text { Braszczyńska } \\
\quad \text { et al. }(1975,1976)\end{array}$ \\
\hline $\begin{array}{l}\text { Oven platforms-before } \\
\text { modernisation }\end{array}$ & & $\begin{array}{l}99(\mathrm{~A}), 112.3(\mathrm{~B}) \\
112,4(\mathrm{C})\end{array}$ & \\
\hline After modernisation & & 25.81 .32 .3 & \\
\hline Coke plants & Poland & & Brzeźnicki (1995) \\
\hline Coke charging man & & 25,$7 ; 3.3$ & Braszczyńska (1989) \\
\hline Coke guide man & & 4,5 & \\
\hline Coke-quenching man & & 0,4 & \\
\hline Coke man & & 2,$6 ; 1.7$ & \\
\hline Coke door man & & 6,$5 ; 25.6$ & \\
\hline Coke plants & Poland & & $\begin{array}{l}\text { Luks-Betlej and } \\
\text { Bodzek (1992) }\end{array}$ \\
\hline \multicolumn{4}{|l|}{ Battery } \\
\hline Coke charging car & & 2.72 & \\
\hline Coke plants & Poland & & Smolik (2001) \\
\hline Battery top & & 5.54 & \\
\hline Battery side & & 3.11 & \\
\hline Battery bottom & & 0.65 & \\
\hline Coke plants & Poland & & $\begin{array}{l}\text { Braszczyńska } \\
\text { et al. (1976) }\end{array}$ \\
\hline \multicolumn{4}{|l|}{ Battery } \\
\hline Coke charging system & & 273.2 & \\
\hline Coke plants & Sweden & & Levin (1995) \\
\hline Battery top ${ }^{a}$ & & 16 & \\
\hline Battery top ${ }^{b}$ & & 4.0 & \\
\hline Coal conveyer ${ }^{c}$ & & 2.6 & \\
\hline Charging car & & 12 & \\
\hline Oven doors ${ }^{\mathrm{a}}$ & & 22 & \\
\hline Oven doors ${ }^{b}$ & & 1.9 & \\
\hline Oven platforms & Sweden & $9.4-13.5$ & $\begin{array}{l}\text { Lindstedt and } \\
\text { Sollenberg (1982) }\end{array}$ \\
\hline Driver of filling container & & $4.7-17$ & \\
\hline $\begin{array}{l}\text { Aluminum plants-various } \\
\text { workplaces }\end{array}$ & Norway & $11.3-854$ & Bjørseth et al. (1978) \\
\hline Coke plants & Finland & & Pyy et al. (1997) \\
\hline Gas worker & & $1.0 ; 2.2^{\mathrm{d}}$ & \\
\hline On the bridge of the larry car & & 5.0 & \\
\hline
\end{tabular}

urinary 1-hydroxypyrene levels are influenced by factors such as diet, industrial pollution, and cigarette smoking. Most previous studies show that the concentrations of urinary 1-hydroxypyrene are correlated with cigarette smoking in a non-occupational population (Van Rooij et al. 1994; Levin 1995). However, other studies show a statistically significant correlation between the levels of 1-hydroxypyrene in human urine and those of pyrene and benzo(a)pyrene in ambient air (Jongeneelen et al. 1986). Smoking has little influence on this correlation when persons smoke less than 20 cigarettes daily in an environment with a relatively high baseline concentration of air-borne PAHs. These observations support the use of 1-hydroxypyrene as a potential biomarker of PAH exposure.

According to Li et al. (2000) the average concentrations of urinary 1-hydroxypyrene were $0.04 \mu \mathrm{mol} / \mathrm{mol}$ creatinine in non-smokers, and $0.20 \mu \mathrm{mol} / \mathrm{mol}$ creatinine in light smokers, $0.46 \mu \mathrm{mol} / \mathrm{mol}$ creatinine in medium smokers, and $1.16 \mu \mathrm{mol} / \mathrm{mol}$ creatinine in heavy smokers. The urinary 1-hydroxypyrene levels of light, medium and heavy smokers were 5, 11, and 28 times higher than those of nonsmokers, respectively. The apparent values (from non- 
detectable to $3.03 \mu \mathrm{mol} / \mathrm{mol}$ creatinine) of urinary 1-hydroxypyrene found in this study are higher and vary greater than those previously reported: $0.07 \pm 0.76 \mu \mathrm{mol} / \mathrm{mol}$ creatinine (Van Rooij et al. 1994). The dose-response correlation is closer than those previously reported (Van Rooij et al. 1994; Boogaard and van Sittert 1995; Göen et al. 1995; Levin 1995). Despite many factors such as sampling, analysis and air quality, the difference may be attributed to the population which may differ in personal smoking characteristics, smoking histories and diets.

It is well known that cigarette smoke contains a variety of potentially toxic components including PAHs. Pyrene from smoking is presumably the main source of 1-hydroxypyrene detected in the cigarette smokers' urine, particularly when compared with non-cigarette smokers. The background urinary 1-hydroxypyrene can be derived from a number of sources such as diets, ambient air, and second hand smoke. The baseline values of urinary 1-hydroxypyrene vary greatly among population subgroups, occupation and air quality (Van Rooij et al. 1994; Levin 1995) Li et al. (2000) found low amounts of 1-hydroxypyrene in nonsmokers' urine and a clear difference in the excretion of urinary 1-hydroxypyrene between non-smokers and smokers who smoked one, two, or three packs of cigarettes per day. This study confirms that 1-hydroxypyrene is a potential biomarker of $\mathrm{PAH}$ exposure from cigarette smoking.

Hansen et al. (2005) concluded that children living in urban residences are more exposed to PAH than children living in rural residences. Time spent outdoors increased the excretion of 1-hydroxypyrene among urban children but less so among rural children. Higher concentrations of ambient air pollution in urban areas may explain this finding. No influence of environmental tobacco smoke, cooking habits, and heating facilities was detected. The present study illustrates the feasibility of obtaining urine samples from a relatively large population of children, in connection with environmental sampling. During the week, the children excreted on average $0.07 \mu \mathrm{mol}$ urinary 1-hydroxypyrene per mol creatinine. Children living in urban residences excreted $0.02 \mu \mathrm{mol}$ more 1-hydroxypyrene than children living in rural residences. This was confirmed in the multiple regression analysis showing a $29 \%$ higher excretion among urban children than rural children. Moreover, the regression analysis showed that for each hour per day spent outside the children excreted $58 \%$ more 1-hydroxypyrene in urine (Hansen et al. 2005).

It should be mentioned that Jacob and Seidel (2002) reviewed the PAH metabolites in human urine as the method of choice to determine occupational and/or environmental exposure of an individual to $\mathrm{PAH}$, in particular, when multiple routes of exposure have to be taken into account. Also, studies using 1-hydroxypyrene or phenan- threne metabolites including its phenols and dihydrodiols were summarized in described work.

\section{Conclusion}

Polycyclic aromatic hydrocarbons (PAHs) comprise the largest class of chemical compounds known to be cancer causing agents. Some, while not carcinogenic, may act as synergists. Some of these PAHs are manufactured for research or are used in medicines, dyes, plastics and pesticides such as naphthalene found in mothballs. PAHs can also be found in coal tar, bitumen, crude oil, creosote and roofing tar.

Thus, potential exposures to chemicals may be assessed by testing contaminated soil, air or water for the chemicals of interest and estimating the degree of intake of each of these media into the human body. In conclusion, the reader is referred to the book (Lichtfouse et al. 2005) for more details associated with review on the actual knowledge about PAHs.

\section{References}

Aamot E, Steinnes E, Schmid R (1996) Polycyclic aromatic hydrocarbons in Norwegian forest soils: impact of long range atmospheric transport. Environ Pollut 92(3):275-280

Allen JO, Dookeran NM, Smith KA, Sarofim AF, Taghizadeh K, Lafleur AL (1996) Measurement of PAHs associated with sizesegregated atmospheric aerosols in Massachusetts. Environ Sci Technol 30:1023-1031

Amellal S, Boivin A, Perrin Ganier C, Schiavon M (2006a) High sorption of phenanthrene in agricultural soils. Agron Sustain Dev 26:99-106

Amellal S, Boivin A, Perrin Ganier C, Schiavon M (2006b) Effect of ageing on mobility and sequestration of phenanthrene in an agricultural soil. Agron Sustain Dev 26:269-275

Anyakora C, Ogbeche A, Palmer P, Coker H (2005) Determination of polynuclear aromatic hydrocarbons in marine samples of Siokolo Fishing Settlement. J Chromatogr Part A 1073:323-330

Ardito G, Badino G, Baker AJ, Orsi M, Ostacoli G, Parodi A (1999) $\mathrm{PAH}$ and heavy-metal biomonitoring along the A32 motorway (North West Italy). In: Proceedings of Fifth International Conference on the Biogeochemistry of Trace Elements. Vienna, Austria

ATSDR (1995) Toxicological profile for polycyclic aromatic hydrocarbons, US Department of Health and Human Services, Public Health Service, Agency for Toxic Substances and Disease Registry, Atlanta, GA

Bae SY, Yi SM, Kim YP (2002) Temporal and spatial variations of the particles size distribution of PAHs and their dry deposition fluxes in Korea. Atmos Environ 36:5491-5500

Baek SO, Goldstone ME, Kirk PWW, Lester JN, Pery R (1991) Concentrations of particulate and gaseous polycyclic aromatic hydrocarbons in London air following a reduction in the Lead content of petrol in the United Kingdom. Sci Total Environ 11:169-199

Baumann PC, Harshbarger JC (1995) Decline in liver neoplasms in wild brown bullhead catfish after coking plant closes and 
environmental PAHs plummet. Environ Health Perspect 103:168-170

Bakker MI, Casado B, Koerselman JW, Tolls J, Kollöffel C (2000) Polycyclic aromatic hydrocarbons in soil and plant samples from the vicinity of an oil refinery. Sci Total Environ 263:91-100

Binet S, Pfohl-Leszkowicz A, Brandt H, Lafontaine M, Castegnaro M (2002) Bitumen fumes: review of work on the potential risk to workers and the present knowledge on its origin. Sci Total Environ Stud 300:37-49

Bjørseth A, Bjørseth O, Fjeldstad PE (1978) Characterization of PAH in Work Atmospheres, Royal Norwegian Council for Scientific and Industrial Research, Oslo, Norway, Report no. 6

Bodzek D, Luks-Betlej K, Warzecha L (1993) Determination of particle-associated polycyclic aromatic hydrocarbons in ambient air samples from the Upper Silesia region of Poland. Atmos Environ 27A:759-764

Boffetta P, Jourenkova N, Gustavsson P (1997) Cancer risk from occupational and environmental exposure to polycyclic aromatic hydrocarbons. Cancer Causes Control 8:444-472

Boogaard PJ, van Sittert NJ (1995) Urinary 1-hydroxypyrene as biomarker of exposure to polycyclic aromatic hydrocarbons in workers in petrochemical industries: baseline values and dermal uptake. Sci Total Environ 163:203-209

Bouloubassi I, Saliot A (1991) Composition and sources of dissolved and particulate PAH from the Rhone delta (NW Mediterranean). Mar Pollut Bull 22:588-594

Braszczyńska Z (1989) Report CPBR 11.5.62. IMP, Sosnowiec (in Polish)

Braszczyńska Z, Linscheid D, Szyja W (1975) Monitoring of particleassociated polycyclic aromatic hydrocarbons at a coking plant. Med Pr 26:4-10

Braszczyńska Z, Linscheid D, Osińska R (1976) Estimation of a new technology in workplace. Med Pr 29:5-11

Broman D, Naef C, Zeburch Y (1991) Long-term high-and-lowvolume air sampling of polychlorinated dibenzo-p-dioxins and dibenzofurans and polycyclic aromatic hydrocarbons along a transect from urban to remote areas on the Swedish Baltic Coast. Environ Sci Technol 25:1841-1850

Brorström-Lundén E, Löfgren C (1998) Atmospheric fluxes of persistent semivolatile organic pollutants to a forest ecological system at the Swedish west coast and accumulation in spruce needles. Environ Pollut 102:139-149

Brorström-Lundén, E, Skärby L (1984) Plants as monitoring samplers of airborne PAH. In: Versino B, Angeletti G (eds) Physicochemical behaviour of atmospheric pollutants. Riedel, Dordrecht

Brunekreef B, Holgate ST (2002) Air pollution and health. Lancet 360(9341):1233-1242

Bryselbout C, Henner P, Carsignol J, Lichtfouse É (2000) Polycyclic aromatic hydrocarbons in highway plants and soils. Evidence for a local distillation effect. Analusis 28:32-35

Brzeźnicki S (1995) Coke plant. In: Wodniak W, Gromca P, Więcka E (eds) Monitoring of polycyclic aromatic hydrocarbons and asbestos in the industry. IMP Łódź

Bucheli TD, Blum F, Desaules A, Gustafsson Ö (2004) Polycyclic aromatic hydrocarbons, black carbon, and molecular markers in soils of Switzerland. Chemosphere 56:1061-1076

Burkhard LP, Lukasewycz MT (2000) Some bioaccumulation factors and biota-sediment accumulation factors for polycyclic aromatic hydrocarbons in lake trout. Environ Toxicol Chem 19:14271429

Butler JD, Butterworth V, Kellow SC, Robinson HG (1984) Some observations on the polycyclic aromatic hydrocarbon (PAH) content of surface soils in urban areas. Sci Total Environ 33:7585

Butler JP, Post GB, Lioy PJ, Waldman JM, Greenberg A (1993) Assessment of carcinogenic risk from personal exposure to benzo(a)pyrene in the total human environmental exposure study (THEES). J Air Waste Manage Assoc 43:970-977

Bylina BG, Rakwic B, Pastuszka JS (2005) Assessment of exposure to traffic-related aerosol and to particle-associated PAHs in Gliwice, Poland. Polish J Environ Stud 14:117-123

Calmano W, Ahlf W, F€orstner U (1996) Sediment quality assessment: chemical and biological approaches. In: Calmano W, Förstner U (eds) Sediments and toxic substances. Springer, Berlin, pp 1-35

Capuano F, Cavalchi B, Martinelli G, Pecchini G, Renna E, Scaroni I, Bertacchi M, Bigliardi G (2005) Environmental prospection for PCDD/PCDF, PAH, PCB and heavy metals around the incinerator power plant of Reggio Emilia town (Northern Italy) and surrounding main roads. Chemosphere 58:1563-1569

Caricchia AM, Chiavarini S, Pezza M (1999) Polycyclic aromatic hydrocarbons in the urban atmospheric particulate matter in the city of Naples (Italy). Atmos Environ 33:3731-3738

Cavret S, Feidt C (2005) Intestinal metabolism of PAH: in vitro demonstration and study of its impact on PAH transfer through the intestinal epithelium. Environ Res 98:22-32

Chen J, Wang X, Tao S, Liu S, Zhang Z, Shen W, Qin B, Sun R, Zhang W (2003) Vertical distribution of polycyclic aromatic hydrocarbons in wastewater irrigated soil in Tianjin area. Urban Environ Urban Ecol 16(6):272-274

Chen L, Ran Y, Xing B, Mai B, He J, Wei X, Fu J, Sheng G (2005) Contents and sources of polycyclic aromatic hydrocarbons and organochlorine pesticides in vegetable soils of Guangzhou, China. Chemosphere 60:879-890

Chetwittayachan T, Shimazaki D, Yamamoto K (2002) A comparison of temporal variation of particle-bound polycyclic aromatic hydrocarbons (pPAHs) concentration in different urban environments: Tokyo, Japan, and Bangkok, Thailand. Atmos Environ 36:2027-2037

Cheung KC, Leung HM, Kong KY, Wong MH (2007) Residual levels of DDTs and PAHs in freshwater and marine fish from Hong Kong markets and their health risk assessment. Chemosphere 66:460-468

Chiang T-A, Wu P-F, Ko Y-Ch (1999) Identification of carcinogens in cooking oil fumes. Environ Res Sec A 81:18-22

Cormier SM, Lin EL, Fulk F, Subramanian B (2000) Estimation of exposure criteria values for biliary polycyclic aromatic hydrocarbons metabolite concentration in white suckers (Catostomus commersoni). Environ Toxicol Chem 19:1120-1126

Council Directive 80/778/EEC of 15 July 1980 Relating to the Quality of Water Intended for Human Consumption Official. J L 229, 30 August 1980, pp. 0011-0029 (http://www.europa.eu.int.)

Crépineau C, Rychen G, Feidt C, Le Roux Y, Lichtfouse É, Laurent F (2003) Contamination of pastures by polycyclic aromatic hydrocarbons (PAHs) in the vicinity of a highway. J Agric Food Chem 51:4841-4845

Dachs J, Bayona JM, Raoux C, Albaigěs J (1997) Spatial, vertical distribution and budget of polycyclic aromatic hydrocarbons in the western Mediterranean seawater. Environ Sci Technol 31:682-688

Davis LC, Castro-Diaz S, Zhang Q, Erickson LE (2002) Benefits of vegetation for soils with organic contaminants. Crit Rev Plant Sci 21:457-491

De Nicola F, Maisto G, Prati MV, Alfani A (2005) Temporal variations in PAH concentrations in Quercus ilex L. (holm oak) leaves in an urban area. Chemosphere 61:432-440

Dyke PH, Foan C, Fiedler H (2003) PCB and PAH releases from power stations and waste incineration processes in the UK. Chemosphere 50:469-480

Edwards NTJ (1983) Polycyclic aromatic hydrocarbons (PAHs) in the terrestrial environment-a review. J Environ Qual 12:427441 
Elskus AA, Stegeman JJ (1989) Induced cytochrome P-450 in Fundulus heteroclitus associated with environmental contamination by polychlorinated biphenyls and polynuclear aromatic hydrocarbons. Mar Environ Res 27:31-45

Evans K, Gill R, Robotham P (1990) The PAH and organic content of sediment particle size fractions. Water Air Soil Pollut 51:13-31

Fang G-C, Wu YS, Chen MH, Ho TT, Huang SH, Rau JY (2004a) Polycyclic aromatic hydrocarbons study in Taichung, Taiwan, during 2002-2003. Atmos Environ. 38:3385-3391

Fang G-C, Chang KF, Lu C, Bai H (2004b) Estimation of PAHs dry deposition and $\mathrm{BaP}$ toxic equivalency factors (TEFs) study at Urban, Industry Park and rural sampling sites in central Taiwan, Taichung. Chemosphere 55:787-96

Fang G-C, Wu YS, Fu PC, Yang IL, Chen MH (2004c) Polycyclic aromatic hydrocarbons in the ambient air of suburban and industrial regions of central Taiwan. Chemosphere 54:443-52

Fang G-C, Wu YS, Fu PC, Chang Ch-N, Chen M-H (2005) Characteristic study of polycyclic aromatic hydrocarbons for fine and coarse particulates at Pastureland near Industrial Park sampling site of central Taiwan. Chemosphere 60:427-433

Fang G-C, Wu YS, Fu PC, Chen M-H, Chang, Ch-N, Ho T-T (2006) Characteristic of polycyclic aromatic hydrocarbon concentrations and source identification for fine and coarse particulates at Taichung Harbor near Taiwan Strait during 2004-2005. Sci Total Environ 366:729-738

Fiedler H, Cheung CK, Wong MH (2002) PCDD/PCDF, chlorinated pesticides and $\mathrm{PAH}$ in Chinese teas. Chemosphere 46:14291433

Fismes J, Perrin-Ganier C, Empereur-Bissonnet P, Morel JL (2002) Soil-to-root transfer and translocation of polycyclic aromatic hydrocarbons by vegetables grown on industrial contaminated soils. J Environ Qual 31:1649-1656

Franzaring J (1997) Temperature and concentration effects in biomonitoring of organic air pollutants. Environ Monit Assess 46:209-220

Fromme H, Oddoy A, Piloty M, Krause M, Lahrz T (1998) Polycyclic aromatic hydrocarbons (PAH) and diesel engine emission (elemental carbon) inside a car and subway train. Sci Total Environ 217:165-173

Fu G, Kan AT, Tomson M (1994) Adsorption and desorption hysteresis of PAHs in surface sediment. Environ Toxicol Chem 13:1559-1567

Fuentes-Rios D, Orrego R, Rudolph A, Mendoza G, Gavilán JF, Barra R (2005) EROD activity and biliary fluorescence in Schroederichthys chilensis (Guichenot 1848): biomarkers of PAH exposure in coastal environments of the South Pacific Ocean. Chemosphere 61:192-199

Gill RA, Jackson RB (2000) Global patterns of root turnover for terrestrial ecosystems. New Phytol 147:13-31

Göen Th, Göundel J, Schaller K-H, Angerer J (1995) The elimination f 1-hydroxypyrene in the urine of the general population and workers with different occupational exposures to PAH. Sci Total Environ 163:195-201

Grayston SJ, Vaughan D, Jones D (1996) Rhizosphere carbon flow in trees, in comparison with annual plants: the importance of root exudation and its impact on microbial activity and nutrient availability. Appl Soil Ecol 5:29-56

Grova N, Laurent C, Feidt C, Rychen G, Laurent F (2000) Gas chromatography-mass spectrometry of polycyclic aromatic hydrocarbons in grass and milk from urban and rural farms. Eur J Mass Spectrom 6:457-460

Grova N, Rychen G, Monteau F, LeBizec B, Feidit C (2006) Effect of oral exposure to polycyclic aromatic hydrocarbons on goat's milk contamination. Agron Sustain Dev 26:195-199

Guerrin MR (1993) Environment tobacco smoke exposure assessment. In: Tobacco smoke. Springer, New York
Guo H, Lee SC, Ho KF, Wang XM, Zou SC (2003) Particleassociated polycyclic aromatic hydrocarbons in urban air of Hong Kong. Atmos Environ 37:5307-5317

Halsall CJ, Coleman PJ, Davis BJ et al (1994) Polycyclic aromatic hydrocarbons in UK urban air. Environ Sci Technol 28:2380 2389

Hansen ÅM, Raaschou-Nielsen O, Knudsen LE (2005) Urinary 1hydroxypyrene in children living in city and rural residences in Denmark. Sci Total Environ 347:98-105

Henner P, Schiavon M, Druelle V, Lichtfouse E (1999) Phytotoxicity of ancient gaswork soils. Effect of polycyclic aromatic hydrocarbons (PAHs) on plant germination. Org Geochem 30:963-969

Hoek G, Brunekreef B, Goldbohm S, Fischer, van den Brandt P, Piet A (2002) Association between mortality and indicators of traffic related air pollution in the Netherlands: a cohort study. Lancet 360(9341):1203-1209

Howsam M, Jones KC, Ineson P (2000) PAHs associated with the leaves of three deciduous tree species. I: concentrations and profiles. Environ Pollut 108:413-424

Howsam M, Jones KC, Ineson P (2001) PAHs associated with the leaves of three deciduous tree species. II: uptake during a growing season. Chemosphere 44:155-164

Hyötyläinen T, Oikari A (2004) Bioaccumulation of PAHs from creosote-contaminated sediment in a laboratory-exposed freshwater oligochaete, Lumbriculus variegates. Chemosphere $57: 159-164$

IARC (1992) IARC Working Group on the Evaluation on Carcinogenic Risk to Humans: Occupational Exposures to Mists and Vapors from Strong Inorganic Acids and Other Industrial Chemicals, vol 54. IARC, Lyon

IARC (International Agency for Research on Cancer) (1983) IARC monographs on the evaluation of the carcinogenic risk of chemicals to human. Polynuclear aromatic compounds, Part I, Chemical, environmental, and experimental data. World Health Organization, Geneva, Switzerland

Jacob J, Seidel A (2002) Biomonitoring of polycyclic aromatic hydrocarbons in human urine. J Chromatogr Part B 778:31-48

JEA (Japanese Environmental Agency) (2000) Report on auto-related environmental taxes; utilization of auto-related taxes in environmental policy. http://www.eic.or.jp/eanet/en/index.html. JEA, Tokyo

Jongeneelen FJ (1994) Biological monitoring of environmental exposure to polycyclic aromatic hydrocarbons; 1-hydroxypyrene in urine of people. Toxicol Lett 72:205-212

Jongeneelen FJ, Bos RP, Anzion RBM, Theuws JLG, Henderson PT (1986) Biological monitoring of polycyclic aromatic hydrocarbons metabolites in urine. Scand J Work Environ Health 12:137143

Jongeneelen FJ, Sheepers PTJ, Groenendijk A, Van Aerts LAGJM, Anzion RBM, Ros RP, Veenstra SJ (1988) Airborne concentrations, skin contamination, urinary metabolite excretion of polycyclic aromatic hydrocarbons among paving workers exposed to coal tar derived road tars. Am Ind Hyg Assoc 49:600-607

Jouraeva VA, Johnson DL, Hassett JP, Nowak DJ (2002) Differences in accumulation of PAHs and metals on the leaves of Tilia xeuchlora and Pyrus calleryana. Environ Pollut 120:331-338

Kanoh T, Fukuda M, Onozuka H, Kinouchi T, Ohnishi Y (1993) Urinary 1-hydroxypyrene as a marker of exposure to polycyclic aromatic hydrocarbons in environment. Environ Res 62:230-245

King AJ, Readman JW, Zhou JL (2004) Determination of polycyclic aromatic hydrocarbons in water by solid-phase microextractiongas chromatography-mass spectrometry. Anal Chem Acta 523:259-267

Kipopoulou AM, Manoli E, Samara C (1999) Bioconcentration of polycyclic aromatic hydrocarbons in vegetables grown in an industrial area. Environ Pollut 106:369-380 
Kishikawa N, Wada M, Kuroda N, Akiyama S, Nakashima N (2003) Determination of polycyclic aromatic hydrocarbons in milk sample by high-performance liquid chromatography with fluorescence detection. J Chromatogr Part B 789:257-264

Kiss G, Varga-Punchony Z, Rohrbacher G, Hlavay J (1998) Distribution of polycyclic aromatic hydrocarbons on atmospheric aerosol particles of different sizes. Atmos Res 46:253261

Knox RC, Sabatini DA, Canter LW (1993) Subsurface transport and fate processes. Lewis Publishing, Boca Raton

Kong KY, Cheung KC, Wong CRC, Wong MH (2005) Residues of DDTs, PAHs and some heavy metals in fish (Tilapia) collected from Hong Kong and mainland China. J Environ Sci Heal 40:111

Kulkarni P, Venkataraman C (2000) Atmospheric polycyclic aromatic hydrocarbons in Mumbai, India. Atmos Environ 34:2785-2790

Kuo C-Y, Cheng Y-W, Chen Y-W, Lee H (1998) Correlation between the amounts of polycyclic aromatic hydrocarbons and mutagenicity of airborne particulate samples from Taichung City, Taiwan. Environ Res Sec A 78:43-49

Larsson B, Sahlberg G (1982) Polycyclic aromatic hydrocarbons in lettuce. Influence of a highway and an aluminium smelter. In: Cooke M, Dennis AJ, Fisher GL (eds) Polynuclear aromatic hydrocarbons: physical and biological chemistry. Springer, New York, pp 417-426

Laurent C, Feidt C, Lichtfouse É, Grova N, Laurent F, Rychen G (2001) Milk-blood transfer of ${ }^{14} \mathrm{C}$-tagged polycyclic aromatic hydrocarbons (PAHs) in pigs. J Agric Food Chem 49:2493-2496

Laurent C, Feidt C, Grova N, Mpassi D, Lichtfouse É, Laurent F, Rychen $\mathrm{G}$ (2002) Portal absorption of ${ }^{14} \mathrm{C}$ after ingestion of spiked milk with ${ }^{14} \mathrm{C}$-phenanthrene, ${ }^{14} \mathrm{C}$-benzo[a]pyrene or ${ }^{14} \mathrm{C}$ TCDD in growing pigs. Chemosphere 48:843-848

Lehndorff E, Schwark L (2004) Biomonitoring of air quality in the Cologne Conurbation using pine needles as a passive sampler-Part II: polycyclic aromatic hydrocarbons (PAH). Atmos Environ 38:3793-3808

Levin JO (1995) First international workshop on hydroxypyrene as a biomarker for PAH exposure in man-summary and conclusions. Sci Total Environ 163:165-168

Li CK, Kamens RM (1993) The use of polycyclic aromatic hydrocarbons as source signatures in receptor modeling. Atmos Environ 27:523-532

Li CS, Ro YS (2000) Indoor characteristics of polycyclic aromatic hydrocarbons in the urban atmosphere of Taipei. Atmos Environ 34:611-620

Li H, Krieger RI, Li QX (2000) Improved HPLC method for analysis of 1-hydroxypyrene in human urine specimens of cigarette smokers. Sci Total Environ 257:147-153

Lichtfouse É, Budzinski H, Garrigues P, Eglinton TI (1997) Ancient polycyclic aromatic hydrocarbons in modern soils: ${ }^{13} \mathrm{C},{ }^{14} \mathrm{C}$ and biomarker evidence. Org Geochem 26:353-359

Lichtfouse É, Apitz S, Nanny M (1999) The biogeochemistry of polycyclic aromatic hydrocarbons. Org Geochem 30:873-969

Lichtfouse E, Schwarzbauer J, Robert D (eds) (2005) Environmental chemistry. Green chemistry and pollutants in ecosystems, 36-41 chaps. Springer, Berlin

Lin TC, Chang FH, Hsieh JH, Chao HR, Chao MR (2002) Characteristics of polycyclic aromatic hydrocarbons and total suspended particulate in indoor and outdoor atmosphere of a Taiwanese temple. J Hazard Mater A 95:1-12

Lindstedt G, Sollenberg J (1982) Polycyclic aromatic hydrocarbons in the occupational environment. Scand Work Environ Health 8:119

Liu YJ, Zhu LZ, Shen XY (2001) Polycyclic aromatic hydrocarbons (PAHs) in indoor and outdoor air of Hangzhou, China. Environ Sci Technol 35:840-844
Liu YN, Tao S, Dou H, Zhang TW, Zhang XL, Dawson R (2007) Exposure of traffic police to Polycyclic aromatic hydrocarbons in Beijing, China. Chemosphere 66:1922-1928

Lodovici M, Dolara P, Taiti S et al (1994) Polynuclear aromatic hydrocarbons in the leaves of the evergreen tree (Laurus nobilis). Sci Total Environ 153:61-68

Lodovici M, Dolara P, Casalini C, Ciappellano S, Testolin G (1995) Polycyclic aromatic hydrocarbon contamination in the Italian diet. Food Addit Contam 12:703-712

Lodovici M, Akpan V, Casalini C, Zappa C, Dolara P (1998) Polycyclic aromatic hydrocarbon in Laurus nobolis leaves as a measure of air pollution in urban and rural sites of Tuscany. Chemosphere 6:1703-1712

Luks-Betlej K, Bodzek D (1992) Monitoring of exposure to polycyclic aromatic hydrocarbons at a coking plant. Med Pr 43:515-521

Ma LL, Chu SG, Wang XT, Cheng HX, Liu XF, Xu XB (2005) Polycyclic aromatic hydrocarbons in the surface soils from outskirts of Beijing, China. Chemosphere 58:1355-1363

Magee BR, Lion LW, Lemley AT (1991) Transport of dissolved organic macromolecules and their effect on the transport of phenanthrene in porous media. Environ Sci Technol 25:323-331

Maliszewska-Kordybach B (1996) Polycyclic aromatic hydrocarbons in agricultural soils in Poland: preliminary proposals for criteria to evaluate the level of soil contamination. Appl Geochem 11(12):121-127

Manoli E, Samara C (1999) Polycyclic aromatic hydrocarbons in natural waters: sources, occurrence and analysis. Tredns Anal Chem 18:717-428

Manoli E, Voutsa D, Samara C (2002) Chemical characterization and source identification/apportionment of fine and coarse air particles in Thessaloniki, Greece. Atmos Environ 36:949-961

Masih A, Taneja A (2006) Polycyclic aromatic hydrocarbons (PAHs) concentrations and related carcinogenic potencies in soil at a semi-arid region of India. Chemosphere 65:449-456

McDonald SJ, Kennicutt MC, Liu H, Safe SH (1995) Assessing aromatic hydrocarbon exposure in Antarctic fish captured near Palmer and McMurdo stations Antarctica. Arch Environ Contam Toxicol 29:232-240

Meador JP, Stein JE, Reichert WL, Varanasi U (1995) Bioaccumulation of polycyclic aromatic hydrocarbons by marine organisms. Rev Environ Contam Toxicol 143:79-165

Meharg AA, Wright J, Dyke H, Osborn D (1998) Polycyclic aromatic hydrocarbon $(\mathrm{PAH})$ dispersion and deposition to vegetation and soil following a large scale chemical fire. Environ Pollut 99:2936

Menichini E (1992) Urban air pollution by polycyclic aromatic hydrocarbons: levels and source of variability. Sci Total Environ 116:109-135

Menzie CA, Potocki BB, Santodonato J (1992) Exposure to carcinogenic PAHs in the environment. Environ Sci Technol 26:12781284

Merlo F, Bolognesi C, Peluso M, Valerio F, Abbondandolo A, Puntoni R (1997) Airborne levels of polycyclic aromatic hydrocarbons: ${ }^{32} \mathrm{P}$-Postlabeling DNA adducts and micronuclei in white blood cells from traffic police workers and urban residents. J Environ Pathol Toxicol Oncol 16:157-162

Meudec A, Dussauze J, Deslandes E, Poupart N (2006) Evidence for bioaccumulation of PAHs within internal shoot tissues by a halophytic plant artificially exposed to petroleum-polluted sediments. Chemosphere 65:474-481

Mielke HW, Wang G, Gonzales CR, Le B, Quach VN, Mielke PW (2001) PAH and metal mixtures in New Orleans soils and sediments. Sci Tot Environ 281:217-227

Mielke HW, Wang G, Gonzales, ChR, Powell ET, Le B, Quach VN (2004) PAHs and metals in the soils of inner-city and suburban 
New Orleans, Louisiana, USA. Environ Toxicol Pharm 18:243247

Miguel AH, Kirchestetter TW, Harely RA, Hering AV (1998) Onroad emissions of particulate polycyclic aromatic hydrocarbons and black carbon from gasoline and diesel vehicles. Environ Sci Technol 32:450-455

Minoia C, Magnaghi S, Micoli G, Fiorentino ML, Turci R, Angeleri S, Berri A (1997) Determination of environmental reference concentration of six PAHs in urban areas (Pavia, Italy). Sci Total Environ 198:33-41

Moret S, Conte LS (2000) Polycyclic aromatic hydrocarbons in edible fats and oils: occurrence and analytical methods. J Chromatogr 882:245-253

Motelay-Massei A, Ollivion D, Garban B, Teil MJ, Blanchard M, Chevreuil M (2004) Distribution and spatial trends of PAHs and PCBs in soils in the Seine River basin, France. Chemosphere 55:555-565

Mueller KE, Shann JR (2006) PAH dissipation in spiked soil: Impacts of bioavailability, microbial activity, and trees. Chemosphere 64:1006-1014

Müller JF, Hawker DW, Connel DW (1998) Polycyclic aromatic hydrocarbons in the atmospheric environment of Brisbane, Australia. Chemosphere 37:1369-1383

Müller JF, Hawker DW, McLachlan MS, Connel DW (2001) PAHs, PCDD/Fs, PCBs and HCB levels from Brisbane, Australia. Chemosphere 43:507-515

Nadal M, Schuhmacher M, Domingo JL (2007) Levels of metals, PCBs, PCNs and PAHs in soils of a highly industrialized chemical/petrochemical area: temporal trend. Chemosphere 66:267-276

Nakajima D, Yoshida Y, Suzuki S (1995) Seasonal changes in the concentration of polycyclic aromatic hydrocarbons in Azalea leaves and relationship to atmospheric concentrations. Chemosphere 30:409-418

Nam JJ, Song BH, Eom KC, Lee SH, Smith A (2003) Distribution of polycyclic aromatic hydrocarbons in agricultural soils in South Korea. Chemosphere 50:1281-1289

Niederer M, Maschka-Selig A, Hohl C (1995) Monitoring polycyclic aromatic hydrocarbons (PAHs) and heavy metals in urban soil, compost and vegetation. Environ Sci Pollut Res 2:83-89

Niu J, Chen J, Martens D, Quan X, Yang F, Kettrup A, Schramm KW (2003) Photolysis of polycyclic aromatic hydrocarbons adsorbed on spruce [Picea abies (L.) Karst] needles under sunlight irradiation. Environ Pollut 123:39-45

Omar NYMJ, Abas MRB, Ketuly KA, Tahir NM (2002) Concentrations of PAHs in atmospheric particles (PM-10) and roadside soil particles collected in Kuala Lumpur, Malaysia. Atmos Environ 36:247-254

Pandit GG, Srivastava PK, Mohan Rao AM (2001) Monitoring of indoor volatile organic compounds and polycyclic aromatic hydrocarbons arising from kerosene cooking fuel. Chemosphere 279:159-165

Panshin SY, Hites RA (1994) Atmospheric concentrations of polychlorinated biphenyls in Bloomington, Indiana. Environ Sci Technol 28:2008-2013

Papageorgopoulou A, Manoli E, Touloumi E, Samara C (1999) Polycyclic aromatic hydrocarbons in the ambient air of Greek towns in relation to other atmospheric pollutants. Chemosphere 39:2183-2199

Park SS, Kim YJ, Kang CH (2002) Atmospheric polycyclic aromatic hydrocarbons in Seoul, Korea. Atmos Environ 36:2917-2924

Perico A, Gottardi M, Boddi V, Bavazzano P, Lanxciotti E (2001) Assessment of exposure to Polycyclic Aromatic Hydrocarbons in police in Florence, Italy, throught personal air sampling and biological monitoring of the urinary metabolite hydroxypyrene. Arch Environ Health 56:512-513
Perugini M, Visciano P, Giammarino A, Manera M, Di Nardo W, Amorena M (2007) Polycyclic aromatic hydrocarbons in marine organisms from the Adriatic Sea, Italy. Chemosphere 66:19041910

Phillips DH (1999) Polycyclic aromatic hydrocarbons in the diet. Mutat Res Genet Toxicol Environ Mutagen 443:139-147

Piccardo MT, Stella A, Redaelli A, Minoia C, Valerio F (2003) Newsagents personal exposures to benzo(a)pyrene in Genoa, Italy. Atmos Environ 37:603-613

Piccardo MT, Stella A, Redaelli A, Balducci D, Coradeghini R, Minoia C, Valerio F (2004) Personal daily exposures to benzo $(a)$ pyrene of taxi drivers in Genoa, Italy. Sci Total Environ 330:39-45

Pyy L, Mäkelä M, Hakal E, Kakko K, Lapinlampi T, Lisko A, Yrjänheikki E, Vähäkangas K (1997) Ambient and biological monitoring of exposure to polycyclic aromatic hydrocarbons at a coking plant. Sci Total Environ 199:151-158

Quantin C, Joner EJ, Portal JM, Berthelin J (2005) PAH dissipation in a contaminated river sediment under oxic and anoxic conditions. Environ Pollut 134:315-322

Raiyani CV, Shah JA (1993) Levels of PAHs in ambient environment of Ahmedabad city. Indian J Environ Protect 13:206-215

Rauret G, Llauradó M, Tent J, Rigol A, Alegre LH, Utrillas MJ (1994) Deposition on holm oak leaf surface of accidentally released radionuclides. Sci Total Environ 157:7-16

Ravindra, Mittal AK, Grieken RV (2001) Health risk suspended particulate matter with special reference to PAHs: a review. Rev Environ Health 16:169-189

Reeves WR, McDonald TJ, Cizmas L, Donnelly KC (2004) Partitioning and desorption behavior of polycyclic aromatic hydrocarbons from disparate sources. Sci Total Environ 332:183-192

Rehwagen M, Müller A, Massolo L, Herbath O, Ronco A (2005) Polycyclic aromatic hydrocarbons associated with particles in ambient air from urban and industrial areas. Sci Total Environ 348:199-210

Reynolds WJ, Feist SW, Jones GJ, Lyons BP, Sheahan DA, Stentiford GD (2003) Comparison of biomarker and pathological responses in flounder (Platichthys flesus L.) induced by ingested polycyclic aromatic hydrocarbon (PAH) contamination. Chemosphere 52:1135-1145

Ringuette S, Germain A, Gonthier C, Perron F (1993) Presence of PAHs in the Canadian Environment-An Overview. (Priority substances list supporting document no. 2) Canadian Environmental Protection Act. Environment Canada, Québec Region

Rockens E, Dumollin J, Matheeussen C (2000) PM $_{10}$ dust and chemical characterisation of aerosols in Flanders, Belgium. Adv Air Pollut 8:699-707

Rogge WF, Hildemann LM, Mazurek MA (1993) Sources of the fine organic aerosol 3. Road dust, tire debris, and organometallic brake lining dust: roads as sources and sinks. Environ Sci Technol 27:1892-1904

Sakai R, Siegmann HC, Sato H, Voorhees AS (2002) Particulate matter and particle-attached polycyclic aromatic hydrocarbons in the indoor and outdoor air of Tokyo measured with personal monitors. Environ Res Sec A 89:66-71

Salomons W (1995) Long-term strategies for handling contaminated sites and large-scale areas. In: Salomons W, Stigliani W (eds) Biogeodynamics of pollutants in soils and sediments. Springer, Berlin, pp 1-30

Santasiero A, Settimo G, Cappiello G, Viviano G, Dell'Andrea E, Gentilini L (2005) Urban crematoria pollution related to the management of the deceased. Microchem J 79:307-317

Schreiber L, Schönherr J (1992) Uptake of organic chemicals in conifer needles: surface adsorption and permeability of cuticles. Environ Sci Technol 26:153-159 
Seigmann K, Scherrer L, Siegmann HC (1999) Physical and chemical properties of airborne nanoscales and how to measure the impact on human health. J Mol Struct (Teochem) 458:191-201

Sharma H, Jain VK, Khan ZH (2007) Characterization and source identification of polycyclic aromatic hydrocarbons (PAHs) in the urban environment of Delhi. Chemosphere 66:302-310

Sheu HL, Lee WJ, Lin SJ, Fang G-C, Chang HC, You WC (1997) Particle bound $\mathrm{PAH}$ content in ambient air. Environ Pollut 96:369-82

Simonich SL, Hites RA (1994) Vegetation-atmosphere partitioning of polycyclic aromatic hydrocarbons. Environ Sci Technol 28:939943

Simonich SL, Hites RA (1995) Organic pollutant accumulation in vegetation. Environ Sci Technol 29:2905-2914

Simpson SL, Burston VL, Jolley DF, Chau K (2006) Application of surrogate methods for assessing the bioavailability of PAHs in sediments to a sediment ingesting bivalve. Chemosphere 65:2401-2410

Smith DJT, Harrison RM (1996) Concentrations, trends and vehicle source profile of polynuclear aromatic hydrocarbon concentrations in the UK atmosphere. Atmos Environ 30:2513-2525

Smolik E (2001) Exposure to PAHs at a coking plant. Med Pr 3:77-81

Song YF, Jing X, Fleischmanna S, Wilke BM (2002) Comparative study of extraction methods for the determination of PAHs from soils and sediments. Chemosphere 48:993-1001

Song YF, Zhou QX, Gong P, Sun TH (2005) Ecotoxicity of soils contaminated with industrial and domestic wastewater in western Shenyang China. Sci China Ser C Life Sci 48 (Suppl):48-56

Song YF, Wilke B-M, Song YX, Gong P, Zhou QX, Yang GF (2006) Polycyclic aromatic hydrocarbons (PAHs), polychlorinated biphenyls (PCBs) and heavy metals (HMs) as well as their genotoxicity in soil after long-term wastewater irrigation. Chemosphere 65:1859-1868

Spitzer T, Kuwatsuka S (1993) Residue levels of polynuclear aromatic compounds in urban surface soil from Japan. J Chromatogr 643:305-317

Srogi K (2007) Human exposure to polycyclic aromatic hydrocarbons (PAHs) from coke plant. Air Protec Waste Probl 2:45-51

Sverdrup LE, Krogh PH, Nielsen T, Kjaer C, Stenersen J (2003) Toxicity of eight polycyclic aromatic compounds to red clover (Trifolium pratense), ryegrass (Lolium perenne), and mustard (Sinapsis alba). Chemosphere 53:993-1003

Tebaay RH, Welp G, Brummer GW (1993) Gehalt an Polycyclischen Aromatischen Kohlenwasserstoffen (PAK) und deren Verteilungsmuster in unterschiedlivh belasteten Boden. Z Pflanzernernaehr Bodenkd 156:1-10

Thomann RV, Komlos J (1999) Model of biota-sediment accumulation factor for polycyclic aromatic hydrocarbons. Environ Toxicol Chem 18:1060-1068

TMG (Tokyo Metropolitan Government) (2000) Say no! to dirty diesel vehicles. http://www.kankyo.metro.tokyo.jp/dno/ENG/index.ht. TMG, Tokyo

Tolosa I, de Mora S, Sheikholeslami MR, Villeneuve J-P, Bartocci J, Cattini C (2004) Aliphatic and aromatic hydrocarbons in coastal Caspian Sea sediments. Mar Pollut Bull 48:44-60

Trapido M (1999) Polycyclic aromatic hydrocarbons in Estonian soil: contamination and profiles. Environ Pollut 105:67-74

Tremolada P, Burnutt V, Calamari D, Jones KC (1996) Spatial distribution of PAHs in the UK atmosphere using pine needles. Environ Sci Technol 30:3570-3577

TRK-Wert for benzo[ $a]$ pyrene in Bundesarbeitsblatt 10, German Federal Department for Worker Safety, Dortmund, 1989, p 58

Tsai PJ, Shieh HY, Lee WJ, Lai SO (2002) Characterization of PAHs in the atmosphere of carbon black manufacturing workplaces. J Hazard Mater A91:25-42
US EPA (1999) Compendium of methods for the determination of toxic organic compounds in ambient air. Environmental Protection Agency, US Federal Register, Compendium Method TO13A, pp 1-42

Van der Oost R, Heida H, Opperhuizen A, Vermeulen NPE (1991) Bioaccumulation of organic micropollutants in different aquatic organisms: sublethal toxic effects on fish. In: Mayes MA, Baron MG (eds) Aquatic Toxicology and Risk Assessment ASTM STP 1124, vol 14, American Society for Testing and Materials, Philadelphia, pp 166-180

Van Rooij JGM, De Ros JHC, Bodelier-Bade MM, Jongeneelen FJ (1993) Absorption of polycyclic aromatic hydrocarbons through skin human: differences between anatomical sites and individuals. J Toxicol Environ Health 38:355-368

Van Rooij JGM, Veeger MMS, Bodelier-Bade MM, Scheepers PTJ, Jongeneelen FJ (1994) Smoking and dietary intake of polycyclic aromatic hydrocarbons as sources of interindividual variability in the baseline excretion of 1-hydroxypyrene in urine. Int Arch Occup Environ Health 66:55-65

Van der Oost R, van Gastel L, Worst D, Hanraads M, Satumalay K, van Schooten FJ, Heida H, Vermeulen NPE (1994) Biochemical markers in feral roach (Rutilus rutilus) in relation to the bioaccumulation of organic trace pollutants. Chemosphere 29:801-/817

Van der Oost R, Beyer J, Vermeulen NPE (2003) Fish bioaccumulation and biomarkers in environmental risk assessment: a review. Environ Toxicol Pharm 13:57-149

Venkataraman C, Lyons JM, Fiedlander S (1994) Size distribution of aromatic hydrocarbons and elemental carbon, sampling measurement methods and source characterization. Environ Sci Technol 28:535-562

Venkataraman C, Thomas S, Kulkarni P (1999) Size distributions of polycyclic aromatic hydrocarbons-gas/particle partitioning to urban aerosols. J Aerosol Sci 30:759-770

Verweij F, Booij K, Satumalay K, van der Molen N, van der Oost R (2004) Assessment of bioavailable PAH, PCB and OCP concentrations in water, using semipermeable membrane devices (SPMDs), sediments and caged carp. Chemosphere 54:16751689

Viau C, Carrier G, Vyckocil A, Dodd C (1995) Urinary excretion kinetics of 1-hydroxypyrene in volunteers exposed to pyrene by the oral and dermal route. Sci Total Environ 163:179-186

Viguli J, Verde J, Irabien A (2002) Environmental assessment of polycyclic aromatic hydrocarbons (PAHs) in surface sediments of the Santander Bay, Northern Spain. Chemosphere 48:157-165

Vyskocil A, Fiala Z, Fialova D, Krajak V, Viau C (1997) Environmental exposure to polycyclic aromatic hydrocarbons in Czech Republic. Hum Exp Toxicol 16:589-597

Vyskocil A, Fiala Z, Chénier V, Krajak V, Ettlerova E, Bukac J, Viau C, Emminger S (2000) Assessment of multipathway exposure of small children to PAH. Environ Toxicol Pharm 8:111-118

Wagrowski DM, Hites RA (1997) Polycyclic aromatic hydrocarbon accumulation in urban, suburban, and rural vegetation. Environ Sci Technol 31:279-282

Wang DT, Meresz O (1982) Occurrence and potential uptake of polynuclear aromatic hydrocarbons of highway traffic origin by proximally grown food crops. In: Cooke M, Dennis AJ, Fisher GL (eds) Polynuclear aromatic hydrocarbons: physical and biological chemistry. Springer, New York, pp 885-896

Wang XL, Tao S, Dawson RW, Xu FL (2002) Characterizing and comparing risks of polycyclic aromatic hydrocarbons in a Tianjin wastewater-irrigated area. Environ Res 90:201-206

Wania F, Haugen JE, Lei YD, Mackay D (1998) Temperature dependence of atmospheric concentrations of semivolatile organic compounds. Environ Sci Technol 32:1013-1021 
Watts WA, Ballestero TP, Gardner KH (2006) Uptake of polycyclic aromatic hydrocarbons (PAHs) in salt marsh plants Spartina alterniflora grown in contaminated sediments. Chemosphere 62:1253-1260

Weiss P, Riss A, Gschmeidler E, Schentz H (1994) Investigation of heavy metal, PAHs, PCB patters and PCDD/F profiles of soil samples from an industrialized urban area (Linz, Upper Austria) with multivariate statistical methods. Chemosphere 29:22232236

WHO (1987) Polynuclear aromatic hydrocarbons (PAHs). In: Air quality guidelines for Europe. Copenhagen, World Health Organization Regional Office for Europe, pp 105-117

WHO (1998) Guidelines for drinking-water quality, 2nd edn. World Health Organization, Geneva, pp 123-152

Wilcke W, Muller S (1999) Polycyclic aromatic hydrocarbons in hydromorphic soils of the tropical metropolis Bangkok. Geoderma 91:297-309

Wilcke W, Zech W, Kobza J (1996) PAH-pools in soils along a PAHdeposition gradient. Environ Pollut 92:307-313

Wilcke W, Lillienfein J, do Carmo Lima S (1999) Contamination of highly weathered urban soils in Uberlandia, Brazil. J Plant Nutr Soil Sci 162:539-548

Wilcke W, Amelung W (2000) Persistent organic pollutants in native grassland soils along a climosequence in North America. Soil Sci Soc Am J 64:2140-2148

Wild SR, Jones KC (1995) Polynuclear aromatic hydrocarbons in the UK environment: a preliminary source inventory and budget. Environ Pollut 88:91-108

Wild SR, Waterhouse KS, McGrath SP, Jones KC (1990) Organic contaminants in an agricultural soil with a known history of sewage sludge amendments: polycyclic aromatic hydrocarbons. Environ Sci Technol 24:1706-1711
Wu SP, Tao S, Liu WX (2006) Particle size distributions of polycyclic aromatic hydrocarbons in rural and urban atmosphere of Tianjin, China. Chemosphere 62:357-367

Yang SYN, Connell DW, Hawker DW (1991) PAHs in air, soil, and vegetation in the vicinity of an urban roadway. Sci Total Environ 66:127-136

Yang HH, Lai SO, Hsieh LT, Hsueh HJ, Chi TW (2002) Profiles of PAH emission from steel and iron industries. Chemosphere 48:1061-1074

Yang HH, Hsieh LT, Liu HS, Mi HH (2005) Polycyclic aromatic hydrocarbon emissions from motorcycles. Atmos Environ 39:17-25

Yunker MB, Macdonald RW, Vingarzan R, Mitchell RH, Goyette D, Sylvestre S (2002) PAHs in the Fraser River basin: a critical appraisal of PAH ratios as indicators of PAH source and composition. Org Geochem 33:489-515

Zhao Z-H, Quan W-Y, Tian D-H (1992) The relationship between polynuclear aromatic hydrocarbons in ambient air and 1hydroxypyrene in human urine. J Environ Sci Health A 27:1949-1955

Zhou J, Wang T, Huang Y, Mao T, Zhong N (2005) Size distribution of polycyclic aromatic hydrocarbons in urban and suburban sites of Beijing, China. Chemosphere 61:792-799

Zhu L, Wang J (2003) Sources and patterns of polycyclic aromatic hydrocarbons pollution in kitchen air, China. Chemosphere 50:611-618

Zhu LZ, Amagai Y, Takahashi T (1997) High sensitive automatic analysis of polycyclic aromatic hydrocarbons in indoor and outdoor air. Talanta 45:113-118 